\title{
Cationic graphene oxide nanoplatform mediates miR-IOI delivery to promote apoptosis by regulating autophagy and stress
}

This article was published in the following Dove Press journal: International Journal of Nanomedicine

\author{
Akram Assali' \\ Omid Akhavan ${ }^{2}$ \\ Fatemeh Mottaghitalab' \\ Mohsen Adeli ${ }^{3}$ \\ Rassoul Dinarvand' \\ Shayan Razzazan ${ }^{4}$ \\ Ehsan Arefian ${ }^{5}$ \\ Masoud Soleimani ${ }^{6}$ \\ Fatemeh Atyabi'
}

'Nanotechnology Research Center, Faculty of Pharmacy, Tehran University of Medical Sciences, Tehran, Iran; ${ }^{2}$ Department of Physics, Sharif University of Technology, Tehran, Iran; ${ }^{3}$ Department of Biology, Chemistry, Pharmacy, Institute of Chemistry and Biochemistry, Freie University Berlin, Berlin, Germany; ${ }^{4}$ Department of Electrical Engineering, Amirkabir University of Technology, Tehran, Iran; ${ }^{5}$ Molecular Virology Lab, Department of Microbiology, School of Biology, College of Science, University of Tehran, Tehran, Iran; ${ }^{6} \mathrm{Hematology}$ Department, Faculty of Medical Sciences, Tarbiat Modares University, Tehran, Iran

Correspondence: Fatemeh Atyabi Nanotechnology Research Center, Faculty of Pharmacy, Tehran University of Medical Sciences, PO Box I4I76/44II,

Tehran, Iran

Tel +98 2l 66959052

Email atyabifa@tums.ac.ir
Introduction: MicroRNA-101 (miR-101) is an intense cancer suppressor with special algorithm to target a wide range of pathways and genes which indicates the ability to regulate apoptosis, cellular stress, metastasis, autophagy, and tumor growth. Silencing of some genes such as Stathmin 1 with miR-101 can be interpreted as apoptotic accelerator and autophagy suppressor. It is hypothesized that hybrid microRNA (miRNA) delivery structures based on cationized graphene oxide (GO) could take superiority of targeting and photothermal therapy to suppress the cancer cells.

Materials and methods: In this study, GO nanoplatforms were covalently decorated with polyethylene glycol (PEG) and poly-L-arginine (P-L-Arg) that reduced the surface of GO and increased the near infrared absorption $\sim 7.5$-fold higher than nonreduced GO.

Results: The prepared nanoplatform [GO-PEG-(P-L-Arg)] showed higher miRNA payload and greater internalization and facilitated endosomal scape into the cytoplasm in comparison with GO-PEG. Furthermore, applying P-L-Arg, as a targeting agent, greatly improved the selective transfection of nanoplatform in cancer cells (MCF7, MDA-MB-231) in comparison with immortalized breast cells and fibroblast primary cells. Treating cancer cells with GO-PEG-(PL-Arg)/miR-101 and incorporating near infrared laser irradiation induced 68\% apoptosis and suppressed Stathmin1 protein.

Conclusion: The obtained results indicated that GO-PEG-(P-L-Arg) would be a suitable targeted delivery system of miR-101 transfection that could downregulate autophagy and conduct thermal stress to activate apoptotic cascades when combined with photothermal therapy.

Keywords: miR-101, cationized graphene oxide, poly-L-arginine, apoptosis, autophagy, photothermal therapy

\section{Introduction}

MicroRNAs (miRNAs) are promising biomolecules to kill cancer cells by regulating various functions of cells, including apoptosis, autophagy, proliferation, differentiation, invasion, metastasis, and stress. ${ }^{1}$ MicroRNA-101 (miR-101) is one of the important regulatory factors which is downregulated in different cancers such as liver, ${ }^{2}$ prostate, ${ }^{2}$ breast ${ }^{3}$ bladder, ${ }^{4}$ colon, ${ }^{4}$ pancreatic, ${ }^{4}$ and lung cancer. ${ }^{2,4}$ MiR-101 could inhibit the Zeste homolog 2 (EZH2) and myeloid cell leukemia-1 (Mcl-1) genes that consequently results in boosting apoptosis, ${ }^{2,3}$ decreasing proliferation, and preventing metastatic tumor growth. ${ }^{2,4}$ Moreover, miR-101 is able to suppress Ras-related protein Rab-5A (RAB5A) and autophagy-related 4D, cysteine peptidase (ATG4D) proteins that play an important role in inhibiting the autophagy. ${ }^{5}$ In fact, the process of autophagy digests the cell components that commonly participates in suppressing apoptotic pathways and promotes cell viability. ${ }^{6,7}$ MiR-101 also participates in adjusting the stability and 
transcriptional function of P53 through downregulation of Stathmin 1 that strongly suppresses the cellular proliferation, invasiveness, ${ }^{8}$ and targeting mammalian target of rapamycin/ hypoxia-inducible factor (TOR/HIF) pathway to regulate the expression of heat shock proteins (HSPs). ${ }^{1,6}$ Interestingly, Stathmin 1 demonstrates as one of the important therapeutic targets $^{8}$ and a major cellular modulator protein that promotes the autophagy. Furthermore, abnormality in autophagy pathways causes a wide range of disorders such as cancer, cardiovascular, and neurodegenerative diseases. ${ }^{6}$ Some of the nanostructures especially nonbiodegradable objects promote autophagy phenomena..$^{9,10}$ Some reports indicated that the cationic nanoplatforms could internalize with endocytosis via joining to autophagosomes and activating the autophagy. ${ }^{10}$ In the case of nonspecific targeting, one of impressive problems is activated autophagy response in nontarget cells that causes dysregulation in noncancerous cells. ${ }^{7}$ To detect the privilege advantage of miR-101, our study needs a special delivery system that targets breast cancer cells, takes high payload of microRNA (miRNA), and swiftly internalizes to the cells. Until now, various miRNA delivery systems have been detected, whereas nanoplatform-based graphene oxide (GO) has indicated versatile morphology. ${ }^{11-14} \mathrm{GO}$ is categorized in the context of nanoplatform that takes the impressive scientific attention due to immense and extraordinary characteristics such as large surface area, easy functionalized, ${ }^{11}$ suitable conductivity, ${ }^{11}$ high thermal stability, chemical and optical properties, and great potential in biomedical fields. ${ }^{11,15}$ In particular, developing $\mathrm{GO}$ with positive functional groups improves the quality of nanoplatform to load and transport genes. ${ }^{14,15}$ Positive peptides such as cell-penetrating peptides not only internalized into the cell but also could swiftly transport nanostructures. Poly-L-arginine (P-L-Arg) and its derivatives have been considered as the major cell penetration peptides that mediates the import of different cargoes into the cells. ${ }^{16,17}$ They have good interaction with phosphate groups presented on the cell membrane and target glycosaminoglycan receptors, especially heparin sulfate through multivalent interactions. ${ }^{16,18}$ Glycosaminoglycan family receptors are overexpressed in cancerous cells, ${ }^{19}$ which indicated a high affinity to targeted nanoplatforms for these receptors. ${ }^{17}$ Type and length of the targeting agents also indicate the impressive effect on the level of uptake. Therefore, good interaction of targeting agents with transporter proteins on the membrane is the advantage of optimizing density and length of targeting agent. ${ }^{20}$ Furthermore, the functional groups with appropriate length and amine groups can efficiently protect and condense plasmid of DNA or the other double-strand genes due to their negative charges. ${ }^{17}$ Besides that, the covalent interaction of the carboxyl groups of GO with the amine group of peptides or polymers reduces GO (rGO) surface, ${ }^{13}$ which decreases the content of oxygen and increases the conductivity of GO in biological fluid. Therefore, modification techniques such as using polyethylene glycol (PEG) can enhance the dispersity and solubility of GO even in salt or serum for a long time. ${ }^{21}$ In the other aspect, reducing GO boosts the absorption in near infrared (NIR) region that elevates the thermal generation under NIR laser irradiation and widely dominates poor miRNA release. In some studies, thermal therapy was used to release drug or gene from nanoplatforms. ${ }^{13,14}$ In addition, the synergic effects of chemotherapy and external NIR photothermal therapy were confirmed by several reports. ${ }^{13,14}$ Interestingly, high-power laser irradiation on cells could induce necrosis, whereas low-power laser mildly increases the cell temperature that causes an impressive effect in protein structure and cellular mechanisms that activates the apoptotic pathways and heat shock stress (HSS). ${ }^{22}$ HSS indicated contradictory behaviors such as activates caspase pathways of mitochondria that push the cells to apoptosis stage, in contrast HSS synthesizes HSPs to prevent degradation of proteins. ${ }^{1,6}$ Repairing the miss folding of proteins is modulated by HSPs, while protein degradation is adjusted under the control of autophagy and lysosome-dependent systems. ${ }^{6}$ These processes also hamper one of the apoptotic pathways (protein kinase B/phosphatidylinositol 3-kinase [Akt/PI3K] pathway) which protect the viability of cancer cells and improve their resistance to thermal therapy. ${ }^{1}$ HSP expression could also inhibit some apoptotic pathway in cancer cells, ${ }^{22}$ while miR-101 suppresses this action and accelerates the apoptotic cascade in cancer cells.

Here, it is hypothesized that the prepared nanoplatform could enhance the trafficking in cell membrane, and in parallel, thermal therapy could improve the gene release and increase the heat stress. In this purpose, we prepared a novel nanoplatform based on the GO with stable and safe structure to provide an efficient gene carrier. The GO surface was functionalized by amine PEG and P-L-Arg. Reducing the GO surface with covalent bond increased the conductivity of nanoplatform to generate heat. PEGylation could improve the stability and the biocompatibility, while the long linear chains of P-L-Arg induce the interaction with target cells and convert the nanoplatform to a smart structure. Furthermore, the guanidine groups in lateral sides of P-L-Arg facilitate the electrostatic interaction with genes that result in endosomal scape. Thermal therapy can induce the changing in peptide conformation, disrupt the weak electrostatic interaction with gene, and interrupt the endosome/endolysosome. All the 
mentioned features could provide a suitable situation for activating the apoptotic pathways under miR-101 transfection and NIR laser irradiation.

\section{Materials and methods Chemical and reagents}

Hsa-miR-101 and the scramble (5-miR-101) labeled by cyanine 5 (cy5) fluorescent dye were prepared from TAG Copenhagen (Denmark). High-purity graphite powder $(<45 \mu \mathrm{m})$, poly-L-arginine $(70 \mathrm{KD})$, polyethyleneglycol bis

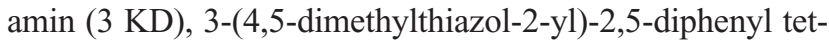
razolium bromide (MTT), fluorescein isothiocyanate (FITC), and $N$-hydroxysuccinimide (NHS) were obtained from SigmaAldrich Co. (St Louis, MO, USA). Sulfuric acid ( $\mathrm{H}_{2} \mathrm{SO}_{4} ; 98 \%$ ), $\mathrm{NaNo}_{3}, \mathrm{KMnO}_{4}, \mathrm{HCL}$, and DMSO were purchased from Merck \& Co., Inc. (Whitehouse Station, NJ, USA). 1-Ethyl-3(3-dimethylaminopropyl) carbodiimide (EDC) was obtained from Acros (NJ, NY, USA). EcoRI and BamH1 restriction enzymes were prepared from Thermo Fisher Scientific (Waltham, MA, USA). Beta-actin antibody (mouse monoclonal), stathmin1 antibody (rabbit polyclonal), and HRP polyclonal secondary antibody were purchased from Abcam (Cambridge, UK). MDA-MB-231 (basal aggressive metastatic, estrogen receptor-negative breast epithelial adenocarcinoma), MCF7 (luminal non-metastatic, estrogen and progesterone receptor-positive breast epithelial adenocarcinoma), MCF10A (immortal and non-transformed epithelial human breast), and HU-02 (primary human foreskin fibroblast) were obtained from the Iranian Biological Resource Center (Tehran, Iran).

\section{Preparation of nanoplatforms Synthesis of GO}

GO was synthesized based on modified Hummer method as described in previous papers. ${ }^{12,13}$ Briefly, graphite powder (4 g) was added to $98 \% \mathrm{H}_{2} \mathrm{SO}_{4}(200 \mathrm{~mL})$ and stirred for $12 \mathrm{~h}$. Purified and dried mixture of first step was diluted with $98 \%$ $\mathrm{H}_{2} \mathrm{SO}_{4}(300 \mathrm{~mL}), \mathrm{NaNO}_{3}(4.0 \mathrm{~g}), \mathrm{KMnO}_{4}(128.0 \mathrm{~g})$, and stirred $(500 \mathrm{rpm})$. After that, the solution was cooled for $1 \mathrm{~h}$ and $800 \mathrm{~mL}$ deionized (DI) water was added. At the end of the reaction, $30 \% \mathrm{H}_{2} \mathrm{O}_{2}(100 \mathrm{~mL})$ was added to the mixture drop by drop. Finally, the solution was washed several times with $10 \% \mathrm{HCl}$ and then washed with DI water, also the product was exfoliated with sonication $(500 \mathrm{~W}$ ) for $3 \mathrm{~h}$ in ice bath. $\mathrm{NaOH}$ $(1.2 \mathrm{~g})$ and chloroacetic acid ( $1 \mathrm{~g})$ were mixed with the GO suspension $(2 \mathrm{mg} / \mathrm{mL}$ ) under sonication and kept for $2 \mathrm{~h}$ which turned the hydroxyl groups of GO to carboxyl. ${ }^{12,13}$ The modified GO was diluted with DI water to reach to $\sim 1 \mathrm{mg} / \mathrm{mL}$ concentration. During the first step of modification, GO was linked to amine PEG via covalent bonds. GO was bath-sonicated with PEG (10 mg) for 5 minutes and then EDC (15 mg) was added to the suspension and bath sonicated for another 30 minutes. NHS (15 mg) was further added to this suspension and stirred in a cold place, overnight. After that, the reaction was terminated by purification using Amicon filter (30 KD) and dispersed in distilled deionized (DD) water. Later, $2 \mathrm{mg}$ P-L-Arg (70 kDa) was mixed with $1 \mathrm{~mL}$ DD water and $5 \mathrm{mg}$ EDC; the mixture was then added to the GO-PEG $(5 \mathrm{~mL}$, $0.3 \mathrm{mg} / \mathrm{mL}$ ) and stirred. After $30 \mathrm{~min}, 5 \mathrm{mg}$ NHS was added to the suspension and stirred overnight at $4{ }^{\circ} \mathrm{C}$. To purify the nanoplatforms solution and separate unbind poly peptide, the mixture was washed by Amicon filter (100 KD) and DD water by centrifuging $(5,000 \mathrm{rpm})$ for 3 times.

\section{Characterization}

Atomic force microscopy (AFM, CP-Research model; VEECO Inc., NY, USA) was used under ambient conditions and in the noncontact mode to detect the size distribution of sheets, thickness of GO, and modified GOs. The hydrodynamic diameters, zeta potential of GO sheets, and nanoplatforms [GO-PEG and GO-PEG-(P-L-Arg)] in DPBS buffer (pH 7.4) were detected using dynamic light scattering (DLS, Malvern Zetasizer, Nano ZS90; Malvern Instruments, Malvern, UK) at room temperature. Fourier transform infrared (FTIR) spectra were obtained using a Nicolet-6700 FTIR spectrophotometer (Thermo Instruments Inc., Santa Fe, NM, USA) by preparing KBr pellets from $400 \mathrm{~cm}^{-1}$ to $4,000 \mathrm{~cm}^{-1}$ to identify the chemical groups of nanostructure and characterize the surface properties. The UV-Vis spectroscopy was performed using a CE7500 (CECIL, Cambridge, UK) to detect the optical density of nanoplatform in each step of coating and modification. Differential scanning calorimetry (DSC) was implemented with thermo analytical technique (Mettler Toledo, Stockholm, Sweden), at a heating rate of $10^{\circ} \mathrm{C} \mathrm{min}^{-1}$ in $\mathrm{N}_{2}$ to visualize the melting point of the components of the structures. Cell viability was evaluated by MTT assay for nanoplatforms and components, whereas apoptosis and the cellular uptake of these structures were detected by using flow cytometer (Attune Applied Biosystems, Foster city, CA, USA) in all cell lines. Complementary DNAs (cDNAs) were prepared by polymerase chain reaction (PCR, PQ lab), and expressions of miR-101 were measured by using realtime PCR (RT-PCR, StepOnePlus; Thermo Fisher Scientific). Fluorescence emission of FITC and cy5 were detected with a confocal microscope (ECLIPSE Ti; Nikon Corporation, Tokyo, Japan). In order to detect protein changes in targeted cells, the amount of protein was evaluated by immunocytochemistry (ICC) and Western blotting (WB) assay. 


\section{NIR-mediated photothermal therapy}

In order to detect the temperature changes during the NIR laser irradiation ( $808 \mathrm{~nm}, 1.2 \mathrm{~W} / \mathrm{cm}^{2}$ for $10 \mathrm{~min}$ ), the nanoplatforms $(4 \mu \mathrm{g} / \mathrm{mL})$ were diluted in distilled water and PBS. The temperature changes were detected every $2 \mathrm{~min}$ by digital thermometer.

\section{Preparation of nanoplatforms/plasmid DNA (pDNA) or double-strand miRNA (dsmiRNA) complexes}

To detect the amount of retarded pDNA (preparation described in supporting information) or dsmiRNA (two purchased strands of miRNA were annealed) with nanoplatforms (Go-PEG-(P-L-Arg), GO-PEG)/pDNA in ratios (0.5-10) and (Go-PEG-(P-L-Arg), GO-PEG)/dsmiRNA in ratio (0.5-5) were incubated at room temperature for 1 h. ${ }^{1,23}$ After that, the stability of the samples was detected by gel electrophoresis ( $120 \mathrm{~V}$ for $20 \mathrm{~min}$ ) with $2 \%$ and $1 \%$ agarose gel for nanoplatforms/dsmiRNA and nanoplatforms/pDNA, respectively. The gels were then stained (SYBER Green) for $20 \mathrm{~min}$ and visualized by UV illuminator. ${ }^{23}$ To indicate the NIR laser effect on miRNA release, the complex of nanoplatforms/ dsmiRNA in PBS was irradiated $\left(1.2 \mathrm{~W} / \mathrm{cm}^{2}\right)$ for $10 \mathrm{~min}$. The nanoplatforms/dsmiRNA samples were collected every $3 \mathrm{~min}$ during irradiation and run by gel electrophoresis.

\section{Cell culture}

MCF10A was cultured in DMEM containing 20\% horse serum, whereas MCF7, MDA-MB-231, and HU-02 were cultured in DMEM with $10 \%$ fetal bovine serum (FBS). The media was supplemented with $100 \mu \mathrm{g} / \mathrm{mL}$ streptomycin and $100 \mathrm{unit} / \mathrm{mL}$ penicillin and maintained at $37^{\circ} \mathrm{C}$ under $5 \% \mathrm{CO}_{2}$. Commonly, the cells were cultured $24 \mathrm{~h}$ before transfection or treatment.

\section{Cell transfection}

For transfection, the cells were cultured in six-well plates and the nanoplatforms/pDNA (4:1) were added to each well and incubated for $1 \mathrm{~h} .{ }^{23}$ Consequently, the supernatant was removed and the cells were washed with PBS and incubated in a fresh medium containing $10 \% \mathrm{FBS}$ for $48 \mathrm{~h}$. To evaluate the transfection efficiency of cells, the expression of GFP was visualized under the fluorescent microscope at $488 \mathrm{~nm}$ excitation wavelength. The cells treated with nanoplatforms without pDNA were used as a control group.

\section{Cytotoxicity assay}

The cellular viability next to the nanoplatforms was assessed by MTT assay at 24,48 , and $72 \mathrm{~h}$ after treatment. About
$4 \times 10^{3}$ cells were seeded in 96 -well plates $24 \mathrm{~h}$ before the experiment. Different concentrations of GO-PEG-P-L-Arg and GO-PEG nanoplatforms $(4,6$, and $12 \mu \mathrm{g} / \mathrm{mL})$ were added to the wells and incubated for 90 min (fixed time of treatment for total cell assay). ${ }^{23}$ After that, the medium was removed and incubated in DMEM with $10 \%$ FBS for another 24, 48, and $72 \mathrm{~h} .{ }^{23}$ Furthermore, the cell viability in the presence of Go-PEG-(P-L-Arg)/miR-101 and GO-PEG/ miR-101 $(4 \mu \mathrm{g} / \mathrm{mL})$ were detected by MTT assay as described above in the same intervals. The cells incubated with nanoplatforms in the presence or absence of miR-101 were also irradiated under NIR laser ( $808 \mathrm{~nm}$ laser, $1.2 \mathrm{~W} / \mathrm{cm}^{2}$ ) for 10 min. The supernatant was replaced with DMEM and $10 \%$ FBS. After incubation for 24, 48, and $72 \mathrm{~h}$, the MTT (4,5-dimethylthiazol-2-yl, $20 \mu \mathrm{L}$ of $5 \mathrm{mg} / \mathrm{mL}$ in $100 \mu \mathrm{L}$ medium) was added to the cells and incubated for $4 \mathrm{~h}$ at $37^{\circ} \mathrm{C}$ and $5 \% \mathrm{CO}_{2}$. Finally, the media were removed and the formazan was dissolved in DMSO $(150 \mu \mathrm{L})$. The absorbance was recorded with an ELISA plate reader (ELX-800, USA) at $490 \mathrm{~nm}$. Relative cell viability was counted as the percentage of viable cells to untreated controls.

\section{Apoptosis assay}

Apoptosis was detected with flow cytometry using Annexin V/PI kit (eBioscience; NJ, NY, USA). For this purpose, the cells were incubated with nanoplatforms $(4 \mu \mathrm{g} / \mathrm{mL})$ and nanoplatforms/miR-101 for $90 \mathrm{~min}$ in six-well plates. In parallel, the cells incubated with nanoplatforms in the presence or absence of miR-101 were also exposed under laser irradiation $\left(808 \mathrm{~nm}\right.$ laser, $1.2 \mathrm{~W} / \mathrm{cm}^{2}$ ) for $10 \mathrm{~min}$. After removing the supernatant, the fresh medium and FBS were added to each well and kept for 24, 48, and $72 \mathrm{~h}$. Finally, the cells were detached from the plate and dyed with Annexin V-FITC/ propidium iodide (PI) (based kit protocol, eBioscience) in a dark room. The rates of apoptosis and necrosis were quantified by flow cytometry (FITC detected at 515-545 nm and PI measured at 564-606 nm).

\section{Cellular uptake}

GO-PEG-(P-L-Arg) and GO-PEG $(6 \mu \mathrm{g} / \mathrm{mL})$ were incubated with $0.1 \mathrm{~mL}$ FITC $(5 \mu \mathrm{M})$ dye. The nanoplatforms/FITC complexes were cleaned with $30 \mathrm{kDa}$ Amicon filter twice to remove the surplus unbound FITC. The nanoplatforms/ FITC were then dispersed in distilled water and incubated in scramble-Cy5 $(1 \mathrm{nM})$ in dark. The cells were seeded in sixwell plates on cover slips $24 \mathrm{~h}$ before transfection. After that, the cells were incubated with $4 \mu \mathrm{g} / \mathrm{mL}$ nanoplatforms/FITC/ scramble-cy5 suspension for $90 \mathrm{~min}$ at $37^{\circ} \mathrm{C}$ and $5 \% \mathrm{CO}_{2}$ and 
rinsed with PBS three times followed by fixing in paraformaldehyde $0.4 \%$ for $20 \mathrm{~min}$ at $4^{\circ} \mathrm{C}$. Afterward, the cell nuclei were stained with DAPI for less than a minute and washed several times with PBS. The cellular uptake was captured by confocal laser microscopy. The excitation/emission bands for FITC and Cy5 were recorded at 493-628 nm and 638-759 nm, respectively. To quantitatively detect the cellular uptake, the cells were incubated with $4 \mu \mathrm{g} / \mathrm{mL}$ nanoplatforms/FITC in six-well plates. After 90 min, the cells incubated with nanoplatforms in the presence or absence of miR-101 were also exposed under laser irradiation (808 $\mathrm{nm}$ laser, $1.2 \mathrm{~W} / \mathrm{cm}^{2}$ ) for $10 \mathrm{~min}$. Afterward, the cells were detached by trypsin and washed with PBS twice. The cellular uptake was then measured quantitatively with flow cytometry that based detection of FITC dye in the considered cells.

\section{Quantitative RT-PCR (qRT-PCR)}

The release and expression of genes in the cells were quantitatively detected by qRT-PCR. For this, the cells were transfected with nanoplatforms/pDNA and nanoplatforms/ dsmiR-101 for $90 \mathrm{~min}$. In addition, the cells incubated with nanoplatforms/dsmiR-101 were also irradiated under NIR laser ( $808 \mathrm{~nm}$ laser, $1.2 \mathrm{~W} / \mathrm{cm}^{2}$ ) for $10 \mathrm{~min}$. After that, the cells treated with nanoplatforms/dsmiR-101 (12 h after treatment) and nanoplatforms/pDNA (48 h after treatment) were detached from plate to purify the RNA according to the commercial RNA purification kit (CinnaGen, Tehran, Iran). Then, the concentration of total RNA was estimated by spectrophotometry (absorbance in $260 \mathrm{~nm}$ ). RNA $(5 \mu \mathrm{g} / \mathrm{mL}$ ) was used for cDNA synthesis. The analysis was followed by RT-PCR (RT primers of miR-101, listed in the Supplementary materials), SYBR Green PCR Master Mix (Takara, Shiga, Japan), and a StepOnePlus RT-PCR System (Applied Biosystems). All the samples were measured triplicate and compared with control (treated only with nanoplatform). Cycle threshold results were evaluated and normalized in comparison with internal control gene (Snord) with rest software.

\section{Immunocytochemistry}

MDA, MCF10A, MCF7, and HU-02 cells were seeded in four-well plates and incubated at $37^{\circ} \mathrm{C}$ and $5 \% \mathrm{CO}_{2}$ for $24 \mathrm{~h}$. As explained above, the cells were treated with GO-PEG-(P-L-Arg)/miR-101 and GO-PEG-(P-L-Arg) as a control $(4 \mu \mathrm{g} / \mathrm{mL})$ for $90 \mathrm{~min}$; after that, they were depleted of media and allowed to cover with fresh DMEM/FBS for $48 \mathrm{~h}$. Consequently, $0.4 \%$ paraformaldehyde was added to each well, and the cells were allowed to fix in $4{ }^{\circ} \mathrm{C}$ for 30 min. The cells were then permeabilized with $0.25 \%(\mathrm{~V} / \mathrm{V})$
Triton X-100 for 10 min and blocked with goat serum 5\% (V/V) for $45 \mathrm{~min}$. Next, dilution (1:500) of primary antibody (anti-Stathmin1) or isotype control (rabbit IGg1) $(100 \mu \mathrm{L})$ in PBS solution (containing 2\% bovine serum albumin [BSA]) was added to each well and incubated at $4{ }^{\circ} \mathrm{C}$, overnight. Afterward, the solution was removed and washed with $1 \%$ $(\mathrm{V} / \mathrm{V})$ tween in PBS. The cells were blocked with $1 \%(\mathrm{~V} / \mathrm{V})$ BSA for $30 \mathrm{~min}$ and dilution (1:100) of secondary antibody (anti-rabbit IGg1) $(100 \mu \mathrm{L})$ in PBS solution (containing 2\% BSA) was added to each well at $37^{\circ} \mathrm{C}$ for $1 \mathrm{~h}$. Finally, the cells were washed with $1 \%(\mathrm{~V} / \mathrm{V})$ tween and stained with DAPI. Complexed antibody with Stathmin1 in treated and control was visualized under a fluorescent microscope (Nikon).

\section{Western blotting}

Gene silencing and alteration in target protein were considered by Western blotting. For this purpose, cells were treated with samples and control then incubated in DMEM/ FBS for $48 \mathrm{~h}$. Proteins of cells were extracted with cold lysis buffer and protease inhibitor from treated cells with sample and control. Maximum $40 \mu \mathrm{L}$ of protein was run by SDSPAGE $(12 \%)$ and transferred to nitrocellulose membrane overnight $\left(4^{\circ} \mathrm{C}\right)$. The membrane was blocked with $5 \%$ skim milk in tris-buffered saline-tween (TBST) for $4 \mathrm{~h}$ and washed with tris-buffered saline (TBS) buffer for $5 \mathrm{~min}$; after that, the primary antibody was diluted in TBST and added to membrane and incubated at $4{ }^{\circ} \mathrm{C}$ overnight. After washing with TBS buffer for $5 \mathrm{~min}$, the membrane was incubated in secondary antibody/TBST for $4 \mathrm{~h}$ on shaker. Finally, the membrane was washed with buffer and treated by enhanced chemiluminescence detection reagent to visualize the presence and intensity of the target protein. ${ }^{9}$

\section{Statistical analysis}

SPSS 16.0 (SPSS Inc., Chicago, IL, USA) was used to analyze the quantitative data comprising two groups. Oneway analysis of variance was used for the samples more than two groups. In all tests, the $P$-values $\leq 0.05$ were considered significant.

\section{Results and discussion Synthesis and characterization of dual modified GO nanoplatform}

\section{Synthesis of dual modified GO nanoplatform}

GO was synthesized with a modified hummers method using chemical exfoliation according to the previous reports. ${ }^{12,13,25}$ To improve the surface modification, the hydroxyl groups of GO sheets were converted to carboxyl groups by chloroacetic 
acid in alkaline situation which induced the conversion of the color from light brown to dark brown. ${ }^{25}$ Consequently, the morphology of GO and modified GO were assessed by AFM and in well agreement with DLS. As shown in Figure $1 \mathrm{~A}_{1}$ and $\mathrm{B}_{1}$, the obtained $\mathrm{GO}$ sheets were $127 \pm 4.7 \mathrm{~nm}$ diameter and $1 \pm 0.2 \mathrm{~nm}$ thickness which showed completely exfoliated GO sheets with high hydrophilicity and monodispersity in water. ${ }^{12}$ After well-optimizing the GO planes, GO was subjected to dual functionalization by using two consecutive steps. First, the amine PEG (3 KD) was conjugated to the carboxylic groups of GO with covalent bonds; thus, the thickness of nanoplatform was increased to $2.37 \pm 0.7 \mathrm{~nm}$ and the diameter was decreased to $57.3 \pm 2.7 \mathrm{~nm}$ (Figure $1 \mathrm{~A}_{2}$ and $\mathrm{B}_{2}$ ). In Figure $1 \mathrm{~B}_{2}$, the stability of GO-PEG nanoplatform was evaluated by dispersing the nanoplatform in PBS, while bare GO was aggregated in the serum or salt solution as described in previous research studies. ${ }^{13,25}$ Second, in order to enhance the cellular uptake and targeting the cancer cells, the linear chains of P-L-Arg (70 kDa) were covalently conjugated to the GO surface. Therefore, the final thickness of the nanoplatforms after the two-step modifications changed to $11.2 \pm 3.07 \mathrm{~nm}$ and the diameter converted to $34.6 \pm 3.2 \mathrm{~nm}$

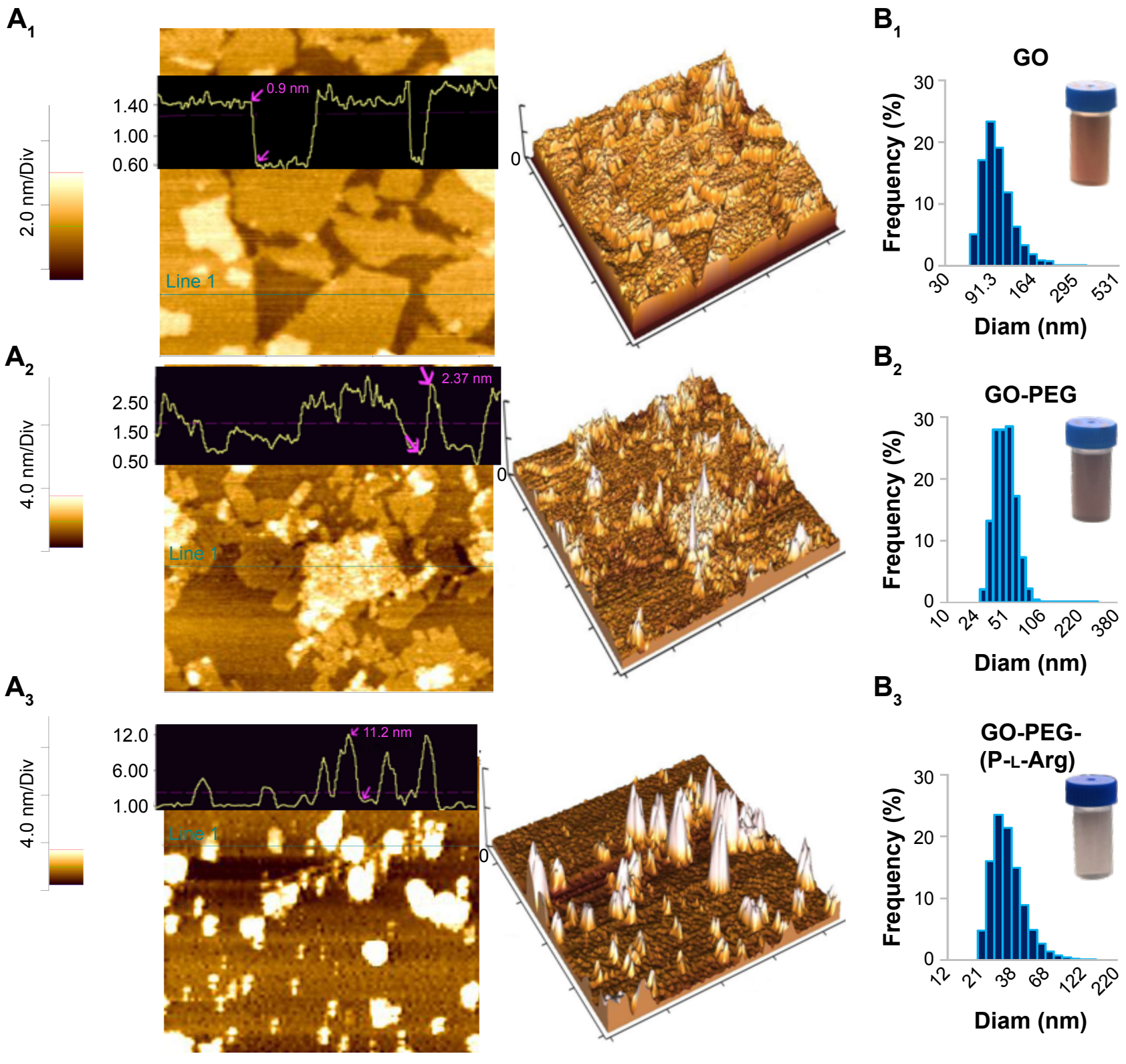

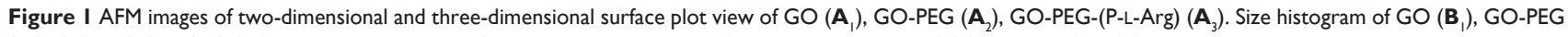
$\left(\mathbf{B}_{2}\right)$, GO-PEG-(P-L-Arg) $\left(\mathbf{B}_{3}\right)$ were measured by DLS and digital photographs of aqueous suspension of GO and modified GO.

Abbreviations: AFM, atomic force microscopy; DLS, dynamic light scattering; GO, graphene oxide; PEG, polyethylene glycol; P-L-Arg, poly-L-arginine; Diam, diameter. 


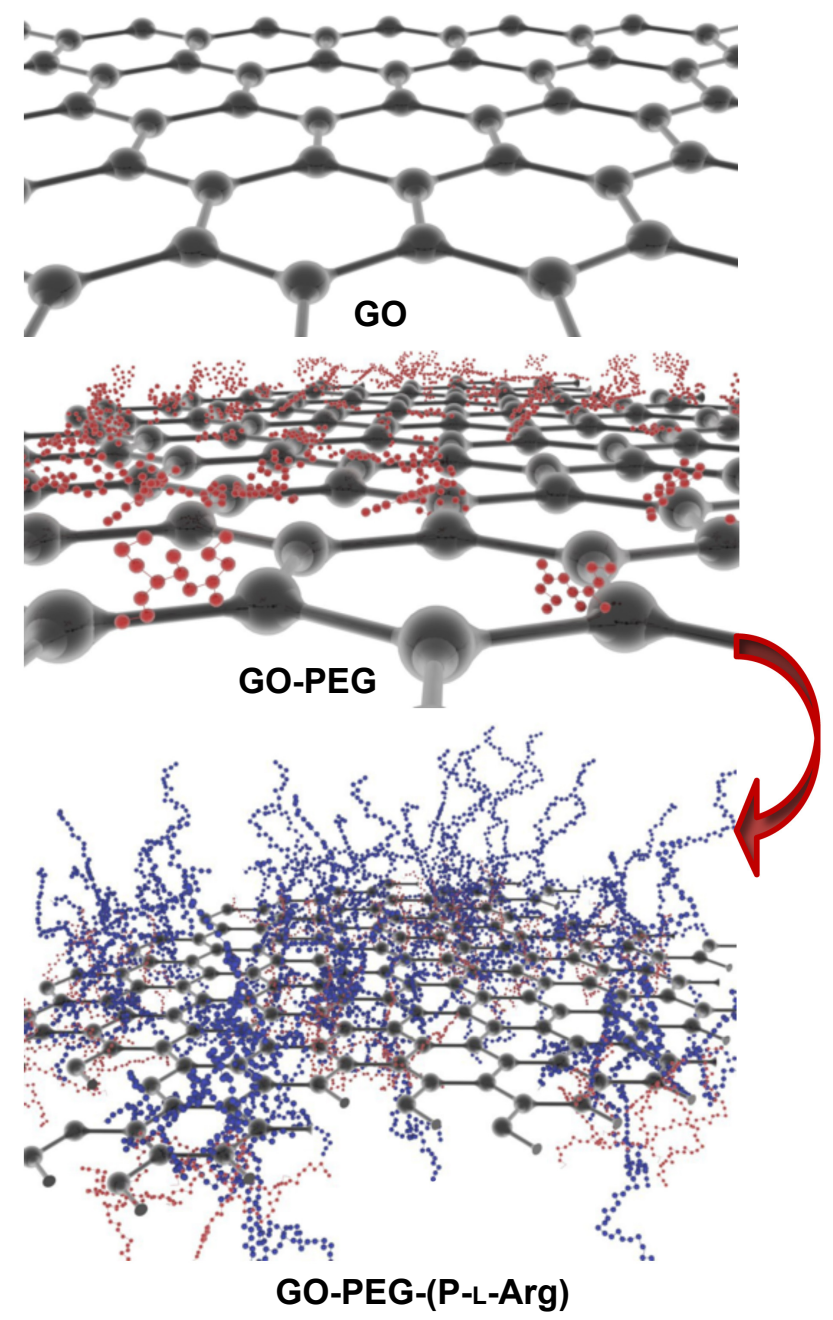

Scheme I Schematic diagram of the hybrid nanoplatform fabrication in dual process on GO sheet.

Abbreviations: GO, graphene oxide; PEG, polyethylene glycol; P-L-Arg, poly-Larginine.

(Figure $1 \mathrm{~A}_{3}$ and $\mathrm{B}_{3}$ ). Schematic representation of $\mathrm{GO}$ and each step of modification was visualized in Scheme 1. Decreasing the size of nanoplatform can be related to the sonication steps during functionalization, while the bare GO sheets were so flexible and hardly shifted to smaller size. Hence, the slight sonication of functionalized GO induced to easily break into smaller size $(<100 \mathrm{~nm})$, which was appropriated for their penetration into the cells. ${ }^{12,25}$ A study described that GOs with size $>100 \mathrm{~nm}$ could not wellinternalize into the cells, whereas GOs with the size $\sim 100 \mathrm{~nm}$ and smaller in lateral dimension may take across the cell membrane perfectly. Their penetration rate in the cells might be hastened when the diameter reach below $40 \mathrm{~nm} .{ }^{15}$ Modification totally changed the smooth face and sharp edges of GO to three-dimensional structure with different morphology and properties. Edges of bare GO can cut the cell membrane and increased the toxicity, while modification covered the sharp edges and modulated the toxicity. ${ }^{15}$ In Figure $1 \mathrm{~B}_{1-3}$, every step of modification was further confirmed by color conversion as described in previous reports. ${ }^{12,13,25}$ The $\zeta$ potentials of GO, carboxylated GO, GO-PEG, and GO-PEG-(P-L-Arg) suspensions were $-31 \pm 3.67,-38 \pm 3.04,8.16 \pm 2.8$, and $32 \pm 4.32 \mathrm{mV}$, respectively. The decrease in $\zeta$ potential of GO after carboxylation confirmed the conversion of hydroxyl groups to carboxyl groups. Negative $\zeta$ potential of GO was shifted to positive charge which is assigned to the presence of amine (GO-PEG) and guanidine groups of GO-PEG-(P-L-Arg) on $\mathrm{GO}$ sheets. This process assisted to increase the affinity of gene to interact with nanoplatform due to the enrichment with amine and guanidine groups. In amine polypeptide-like P-L-Arg, increasing the molecular weight has a direct relationship with the density of charge and increasing toxicity. ${ }^{17}$ Coupling P-L-Arg with biodegradable and biocompatible polymer could solve this limitation. ${ }^{17,18}$ Thus, PEG as a safe and biocompatible polymer could potentially modulate the surface charge and stability. Optical attributes of GO and functionalized GO nanoplatforms were visualized by UV-Vis spectrum (Figure 2A). Intensive absorption of GO spectrum at $230 \mathrm{~nm}$ and shoulder at $300 \mathrm{~nm}$ was emanated from $\pi \rightarrow \pi^{*}$ transitions of $\mathrm{C}=\mathrm{C}$ bond and the $\mathrm{n} \rightarrow \pi *$ transitions of $\mathrm{C}=\mathrm{O}$ bond, respectively. ${ }^{12}$ Covalent functionalization induced the shift in $\mathrm{C}=\mathrm{C}$ bond of $\mathrm{GO}$ from 230 to $266 \mathrm{~nm}$ and reduced the shoulder $(300 \mathrm{~nm})$ that was related to $\mathrm{C}=\mathrm{O}$ bond. ${ }^{26} \mathrm{In}$ addition, the absorption of GO-PEG and GO-PEG-(P-L-Arg) in $808 \mathrm{~nm}$ was increased to 3.7-fold and 7.5-fold, respectively. Covalent functionalization reduced the surface of GO (rGO) nanoplatform and decreased the content of oxygen, which led to some physicochemical changes in the properties of nanoplatform such as increasing the absorbance spectrum and enhancing the electrical conductivity. ${ }^{13,26}$ These properties induced to generate heat from the thin layer of GO and boosted the efficacy of thermal therapy even by using low concentrations of nanoplatforms. ${ }^{14}$

\section{Chemical properties of GO nanoplatform composition}

FTIR spectra of GO indicated the characteristic bonds related to its functional groups (Figure 2B). Briefly, the bonds appeared at 3,300-3,500 $\mathrm{cm}^{-1}, \sim 1,720 \mathrm{~cm}^{-1}, 1,400-1,600 \mathrm{~cm}^{-1}$, and $1,000-1,300 \mathrm{~cm}^{-1}$ were attributed to $-\mathrm{OH}, \mathrm{C}=\mathrm{O}, \mathrm{C}=\mathrm{C}$, and $\mathrm{C}-\mathrm{O}$ bonds, respectively. The content of oxygen confirmed the stability and dispersity of GO sheets in water and the presence of hydroxyl, carboxyl, and carbonyl groups in the synthesized GO. ${ }^{12}$ After modification, some new peaks 
A

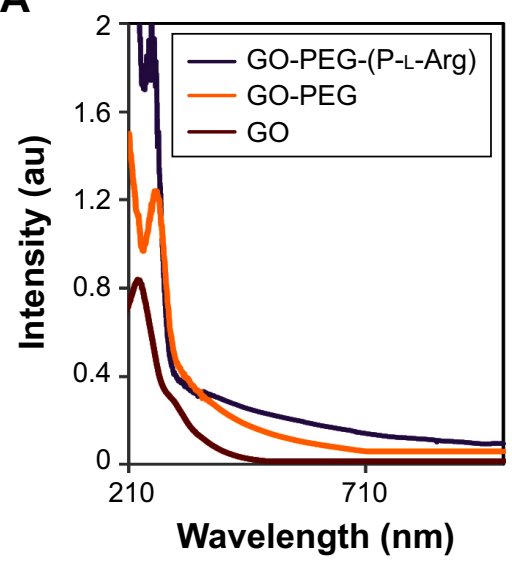

C

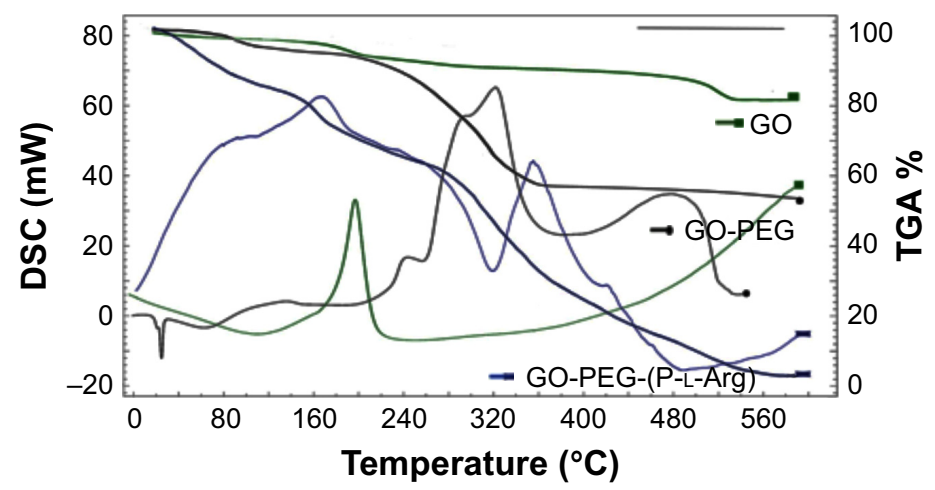

B
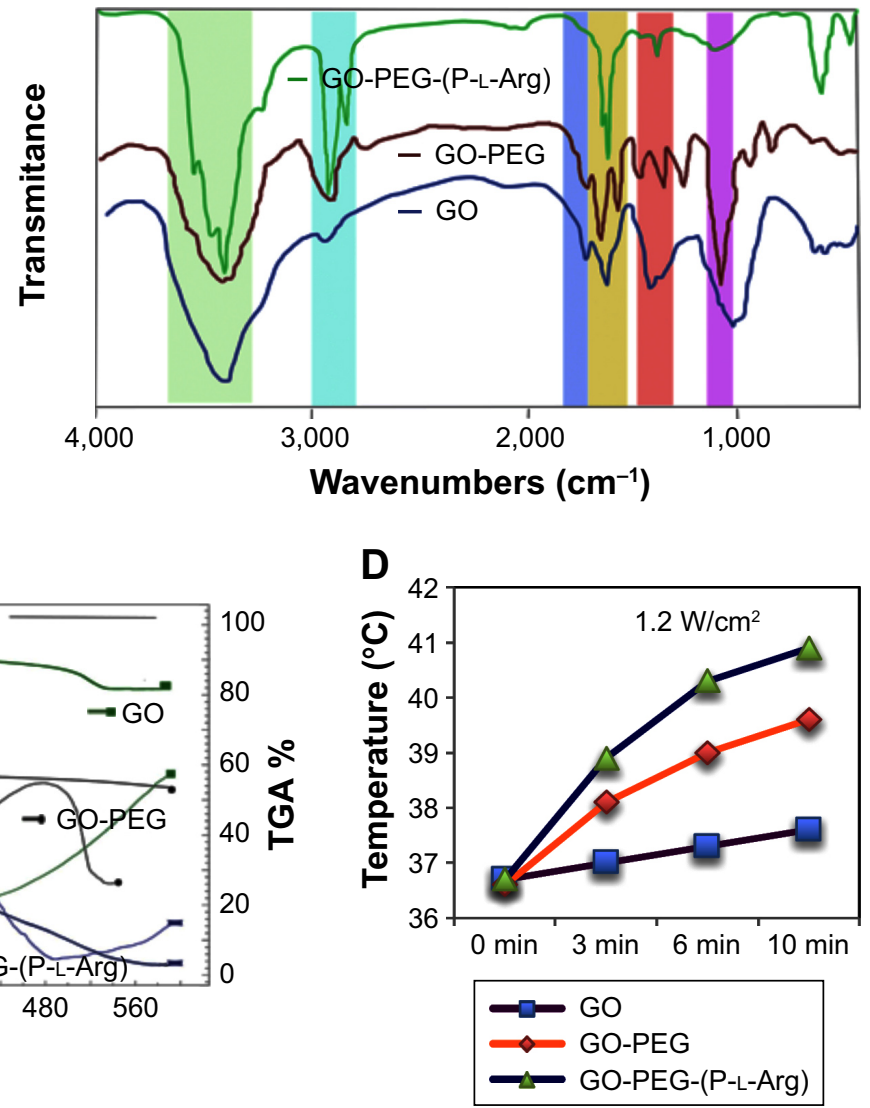

Figure 2 Optical UV-Vis spectra of GO and functionalized GO. GO shows absorbance peak at $230 \mathrm{~nm}$, while functionalized GO induced red shift in C-C bond to $263 \mathrm{~nm}$. Also, absorbance in $808 \mathrm{~nm}$ increased >7-fold due to modification and reduction (A). FTIR spectra of pristine GO and modified single-layer GO (GO-PEG, GO-PEG(P-L-Arg)) (B). TGA and DSC of GO, GO-PEG, and GO-PEG-(P-L-Arg), decomposition takes place up to $600^{\circ} \mathrm{C}$, and scanning rate was evaluated every 10 min (C). Thermal conductivity of GO, GO-PEG, GO-PEG-(P-L-Arg) $(4 \mathrm{mg} / \mathrm{L})$ aqueous suspension in PBS under $808 \mathrm{~nm}$ NIR laser irradiation for 10 min (D).

Abbreviations: DSC, differential scanning calorimetry; GO, graphene oxide; PEG, polyethylene glycol; P-L-Arg, poly-L-arginine; TGA, thermogravimetic analysis; NIR, near infrared; FTIR, Fourier transform infrared.

appeared at $\sim 2,900$ and $\sim 1,100$ corresponding to $\mathrm{C}-\mathrm{H}$ and $\mathrm{C}-\mathrm{O}$ bond, respectively. ${ }^{15}$ Both the functional groups showed the strong bond at $\sim 3,400$ and $\sim 1,600 \mathrm{~cm}^{-1}$, which assigned to the increase in the content of primary amine (two bonds) and secondary amine (one bond). Finally, disappearance of $\sim 1,720 \mathrm{~cm}^{-1}$ bond in two steps of modification confirmed the removal of oxygen from $\mathrm{C}=\mathrm{O}$. The other bond appeared at $\sim 1,640 \mathrm{~cm}^{-1}$ was related to the amide bond, which verified the successful covalent modification of GO. ${ }^{13}$ Figure $2 \mathrm{C}$ shows the DSC in overlay with the thermogravimetric analysis (TGA). DSC was used to determine the melting temperature of components in each step of modification, and in parallel, TGA showed the trend of mass loss. GO lost its weight in two steps, first at $\sim 200^{\circ} \mathrm{C}$ which was related to oxygen-containing groups and the next at $>520^{\circ} \mathrm{C}$ which was related to carbon lattice. ${ }^{21}$ Losing weight in GO-PEG happened with shift in GO mass loss due to the reduction in the content of oxygen $\left(\sim 240^{\circ} \mathrm{C}\right)$ and covalent bond with PEG $\left(\sim 480^{\circ} \mathrm{C}\right)$ and the other portion of mass decreasing occurred between $280^{\circ} \mathrm{C}$ and $380^{\circ} \mathrm{C}$ which was attributed to the polymer structure. ${ }^{21}$ However, the weight loss pattern of GO-PEG-(P-L-Arg) started from $50^{\circ} \mathrm{C}$, whereas the major mass loss was related to the higher temperatures (between $300^{\circ} \mathrm{C}$ and $560^{\circ} \mathrm{C}$ ) which indicated the presence of the amide bond in the structure of the peptide. The amount of PEG and P-L-Arg was also estimated as $\sim 28 \%$ and $\sim 46 \%$ in GO-PEG-(P-L-Arg) nanoplatform. Furthermore, the TGA mass loss was verified by DSC outcomes and demonstrated remodeling of the nanoplatforms (face and properties) due to dual modification.

\section{Thermal properties of GO nanoplatform}

Under continuous laser irradiation $\left(808 \mathrm{~nm} 1.2 \mathrm{~W} / \mathrm{cm}^{2}\right.$ for 10 $\mathrm{min}$ ), the temperatures of GO, GO-PEG, and GO-PEG-(P-L$\operatorname{Arg})(4 \mu \mathrm{g} / \mathrm{mL})$ in PBS solution was increased 1.02-, 1.08-, and 1.115-fold than PBS solution without nanoplatforms, respectively (Figure 2D). Before reducing with amine 
groups, the GO solution indicated no significant increase in temperature. While covalent functionalization decreased content of oxygen on GO surface and convert GO to reduce GO, this process improved the NIR reactivity which enhanced generating heat under NIR laser irradiation. The amount of heat generated was related to the concentration of $\mathrm{rGO}$, power of the laser, and time of irradiation. Interestingly, the intense thermal therapy damaged the cell morphology and induced necrosis ${ }^{22}$ while the increase in cell temperature promotes apoptosis. Adjusting the power of laser and time of irradiation based on the concentration of nanoplatforms caused optimal temperature to activate the apoptosis and decrease the side effects of cancer therapy. ${ }^{22}$

\section{Nanoplatforms in complex with plasmid miR-IOI (pDNA) or double-strand miR-IOI (dsmiR-IOI)}

It is well known that genes have negative charge, unstable structure, and poor cellular uptake, which commonly need a carrier to protect and transport them. ${ }^{24}$ Presented nanoplatforms with guanidine and amine groups had more potential for electrostatic interaction with genes (DNA or RNA). ${ }^{28}$ Chains of polycations as functional groups had stable nanocomplex and transported a wide range of cargoes into the cells, swiftly. ${ }^{20}$ The gel retardation assay was performed to detect the potential of nanoplatforms in complex with plasmid or dsmiRNA (Figure 3A). For this purpose, nanoplatforms/pDNAs with weight ratios of $0.5-10$ were chosen to detect the amount of retardation ( $1 \%$ agarose gel). PDNAs were completely retarded at a weight ratio (nanoplatforms/ pDNA) $>1.4$ by GO-PEG-(P-L-Arg); also it was retarded by GO-PEG at a ratio $\geq 5$ because of short chains of PEG and low $\zeta$ potential. The ultimate $\zeta$ potential of nanoplatforms/ pDNA complexes achieved $+9.2 \mathrm{mV}$ and $-6.8 \mathrm{mV}$ for GOPEG-(P-L-Arg) and GO-PEG, respectively (Figure 3D). pDNA condensation was mostly related to $\zeta$ potential of nanoplatforms, efficacy of amine groups, and length of modification groups. ${ }^{23} \mathrm{P}-\mathrm{L}-\mathrm{Arg}$, as a member of histone with a major role in condensing chromosome, could tightly graft with genes and protected them in comparison with PEI and other polycationic structures. ${ }^{17,21}$ Furthermore, retardation of nanoplatforms/dsmiRNA was measured in a weight ratio from 0.5 to 5 ( $2 \%$ agarose gel). dsmiR-101 in a ratio $>1.2$ and 3.9 were retarded by GO-PEG-(P-L-Arg) and GO-PEG, respectively (Figure $3 \mathrm{~B}$ ). In fact, dsmiR-101 is very small (22 bp) which can be induced to retard easier than pDNA (7,200 bp). GO-PEG indicated no more efficacy for gene delivery due to weakness of gene loading, whereas GOPEG-(P-L-Arg) provided smart structures with high quality to load genes. The final $\zeta$ potential of nanoplatforms $/ \mathrm{dsmiR}$ complexes was achieved to +17.2 and $+4.9 \mathrm{mV}$ for GO-PEG(P-L-Arg) and GO-PEG, respectively (Figure 3D). Based on retardation assay, targeted nanoplatform showed prominent stable complex with high capacity of payload that moderated the $\zeta$ potential of nanoplatforms by the negative charge of the genes. In addition, releasing profile of miR-101 was evaluated
A

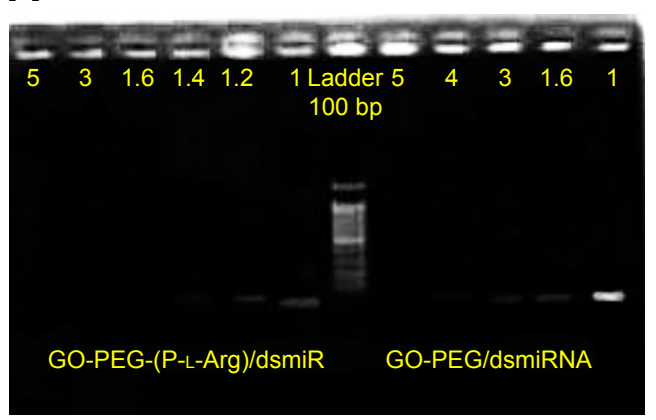

B

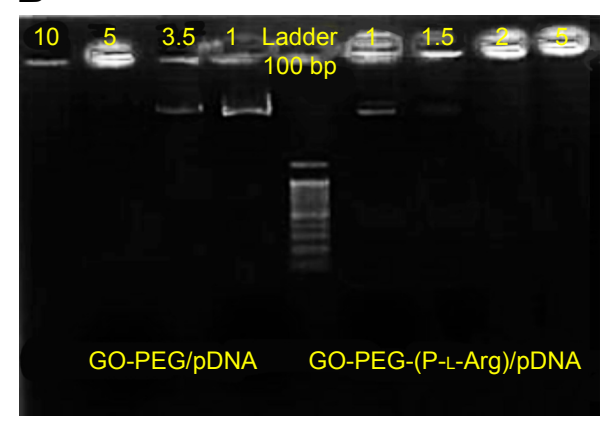

$\zeta$ potential $(\mathrm{mV})$

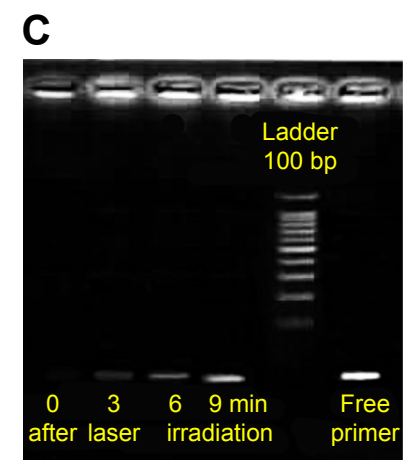

D

\begin{tabular}{llll}
\hline & Nanoplatform & Nanoplatform/dsmiRNA & Nanoplatform/pDNA \\
\hline GO-PEG & $8.16 \pm 2.8$ & $4.9 \pm 2.1$ & $-6.8 \pm 1.4$ \\
GO-PEG-(P-L-Arg) & $32 \pm 4.32$ & $17.2 \pm 2.9$ & $9.2 \pm 3.2$ \\
\hline
\end{tabular}

Figure $3 \mathrm{Gel}$ retardation assay for nanoplatforms/dsmiR-I0I complex ratio between I and 5 (A) and nanoplatform/pDNA ratio between I and I0 (B). Effect of laser irradiation in dsmiR release was detected every 3 min during irradiation (C). Zeta potential of nanoplatform in complex with pDNA and dsmiRNA measured in DD water (D).

Abbreviations: DD, distilled deionized; GO, graphene oxide; PEG, polyethylene glycol; P-L-Arg, poly-L-arginine; pDNA, plasmid DNA; dsmiRNA, double-strand microRNA. 
during laser irradiation by retardation assay in PBS, which was performed every $3 \mathrm{~min}$ during irradiation. As indicated in Figure 3C, NIR laser irradiation mildly increased nanoplatforms temperature, which disrupted interaction of genes and nanoplatforms and enhanced gene release with boosting temperature. ${ }^{21}$ In fact, heat generated from nanoplatforms disrupted the endosome/endolysosome membrane and released the gene from nanoplatforms into the cytosol. ${ }^{21,28}$

\section{Transfection study}

The potency of nanoplatforms in terms of pDNA delivery was detected to further evaluate the transfection efficacy of nanoplatforms, the release of the therapeutic agent, and the possibility of detecting the activity of pDNA. Anionic pDNA was wrapped up with cationic groups of nanoplatforms through electrostatic interaction. ${ }^{21}$ Based on retardation results, nanoplatforms/pDNA (weight ratio 4:1) were incubated with various cell lines to follow the GFP gene expression of pDNA (Figure 4). The GFP expression was evaluated as nanoplatform efficacy by fluorescent microscope after $72 \mathrm{~h}$ (Figure 4). The MCF7 cells treated with GO-PEG-(P-L-Arg)/ pDNA showed the highest expression level in comparison with normal cells. On the other hand, targeted nanoplatforms visualized the best transfection efficacy in breast cancer cell lines that exhibited the targeting effect on cellular internalization, whereas the untargeted nanoplatforms showed less GFP expression in all cell lines, especially in HU-02 primary cells, and no green fluorescence was displayed in the control group (nanoplatforms without pDNA). As described in previous papers, ${ }^{9,18,21}$ GFP expression more effectively visualized the result of polycationic groups in transfection and expression of pDNA. ${ }^{21}$ Also, P-L-Arg properties in target cancer cells induced appreciable extent in transfection and gene therapy. ${ }^{17}$

\section{Evaluation of cytotoxicity}

Dual modification was used to prepare the suitable nanoplatform for gene delivery with the ability to transport cargoes into the cells with minimum activating stress. In order to detect the cytotoxicity of nanoplatforms with different concentrations, we chose two different breast cancer (MCF7, MDA-MB-231 [MDA]) cell lines compared with normal cells (MCF10A [immortalized breast cell line] and HU-02 [primary fibroblast cell]) in 24, 48, and $72 \mathrm{~h}$. The cells were incubated with GO, GO-PEG, and GO-PEG-(P-L-Arg) for 90 min. As it can be seen in Figure S1 (Supplementary materials), GO-PEG-(P-L-Arg) nanoplatform $(12 \mu \mathrm{g} / \mathrm{mL})$ showed significant toxicity on cells, whereas the other doses of the GO-PEG-(P-L-Arg) (4 and $6 \mu \mathrm{g} / \mathrm{mL}$ ) as well as GO and GO-PEG (all doses) did not show any toxicity. Some reports indicated that $\mathrm{GO}$ with the size $>100 \mathrm{~nm}$ had poor uptake and therefore less toxicity ${ }^{18}$ which might be a good declaration for the less toxicity of GO $(\sim 127 \mathrm{~nm})$ obtained from this study. Consequently, we used $4 \mu \mathrm{g} / \mathrm{mL}$ GO-PEG and GO-PEG(P-L-Arg) nanoplatforms as sufficient concentration to deliver genes that had no harm effect on the morphology and biological functions of cells. Despite the high $\zeta$ potential and length of P-L-Arg, this polypeptide represented low toxicity (in prepared concentration) due to no significant damage to the cell morphology and functionality, also P-L-Arg was
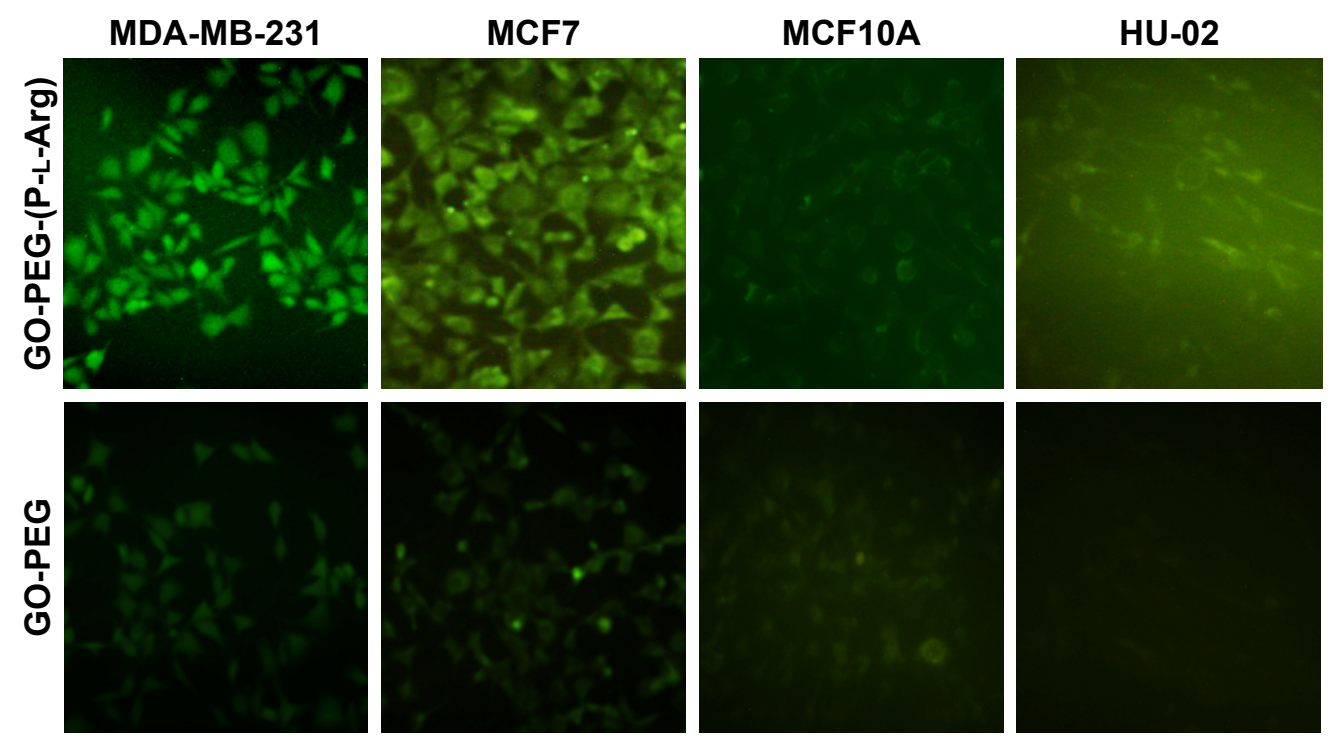

Figure 4 In vitro expression of the GFP gene coupled with GO-PEG-(P-L-Arg) after $48 \mathrm{~h}$ of transfection was detected by fluorescent microscope in all cell lines. Nanoplatforms enhanced cellular uptake efficacy of pDNA upon target cancer cells.

Abbreviations: GO, graphene oxide; PEG, polyethylene glycol; P-L-Arg, poly-L-arginine. 
swiftly digested with the cellular protease without disturbing the cell cycle. ${ }^{17}$ Furthermore, high concentration of P-L-Arg increases the $\zeta$ potential that disturbs the functions of the cells. However, cytotoxicity is commonly related to the cell type and the level of uptake. ${ }^{17}$ Regulating the concentration of P-L-Arg and distributing the GO surface with PEG decreased the density of charge in nanoplatforms. In contrast, many research studies indicated that different types of nanoparticles coated with PEI had high toxicity in a wide range of concentrations that could damage the cell membrane and organelles. ${ }^{23}$ Besides, polymers like PEG and chitosan have low toxicity, but they are not suitable for gene delivery applications because of low potential to retard and transport genes. ${ }^{18,21}$ Transfection with GO-PEG-(P-L-Arg)-dsmiR-101 and GO-PEG-dsmiR-101 complex in all cells was used to detect the effect of miR-101 on cell viability in 24,48 , and 72 h. Figure 5 shows that GO-PEG-(P-L-Arg)-dsmiR-101 decreased the cell viability to $64 \%, 62 \%$, and $76 \%$ in MDA, MCF7, and MCF10A cell lines, respectively. In the same cells, the GO-PEG-miR-101 reduced the cell viability to $87 \%$, $85 \%$, and $87 \%$ after $72 \mathrm{~h}$, whereas in HU-02 cells, the nanoplatforms/miR-101 did not significantly change the cell viability. In parallel, NIR laser ( $808 \mathrm{~nm}, 1.2 \mathrm{~W} / \mathrm{cm}^{2}$ for $10 \mathrm{~min}$ ) was irradiated to the cells treated with nanoplatforms with and without miR-101. The cells treated with GO-PEG-(P-L-Arg)/ dsmiR-101 showed appreciable extent of toxicity and the viability decreased to $32 \%, 35 \%, 53 \%$, and $66 \%$ in MDA, MCF7, MCF10A, and HU-02, respectively. A similar trend was observed in the cells treated with GO-PEG-(P-L-Arg) and GO-PEG without miR-101 in which under the laser irradiation the cellular viability was decreased to $\sim 65 \%$ and $80 \%$ in breast cell lines after $72 \mathrm{~h}$, respectively. Based on the MTT results, GO-PEG-(P-L-Arg)/miR-101 and thermal therapy had a synergic effect in decreasing the viability of cancer cells, dramatically. For further detecting the level of apoptosis, Annexin-V/PI was used in the same situation as MTT assay and time interval $(24,48$, and $72 \mathrm{~h})$ for the MCF7 cell line. Bare nanoplatforms (GO-PEG and GO-PEG-(P-L-Arg)) showed no significant effects on apoptosis or necrosis in all intervals (Figures 6 and 7). GO-PEG-(P-L-Arg) and GO-PEG in complex with miR-101 decreased the cellular viability to $56 \%$ and $87 \%$ after $72 \mathrm{~h}$, respectively. The obtained results strongly revealed the effective role of targeting agent on the internalization and release of miR-101 into the cells. P-L-Arg led to proton sponge effect on endosome that induced the endosomal scape of miR-101. It is confirmed that several mechanisms are activated with miR-101 that are involved in regulating the cell survival and suppressing the expression level of EZH2 and Mcl-1 as anti-apoptotic members of B-cell lymphoma 2 (Bcl-2). ${ }^{3,5}$ It is also well established that downregulation of Stathmin 1 by miR-101 can lead to significant increase in apoptosis by activating the caspase 3, p53, Bcl-2, and induced microtubule instability. ${ }^{8,27}$ In fact, miR-101 is one of the important miRNAs that target the main pathways in the cell cycle. Besides that, the synergic effect of miR-101 and thermal therapy could increase the amount of apoptosis. NIR laser irradiation assisted gene release and activated the apoptotic pathways. Thereupon, the cells treated with GO-PEG-(P-L-Arg)/miR-101 and GO-PEG/miR-101 under laser irradiation induced decrease in the cellular viability to $36 \%$ and $55 \%$, respectively, whereas the cells treated with nanoplatform without miR-101 decreased viability to $71 \%$ and $84 \%$. As confirmed by Annexin V/PI assay, data were in well agreement with MTT assay and indicated apoptosis under miR-101 regulation and laser irradiation. Nanoplatforms/ miR-101 (specially targeted with P-L-Arg) induced more toxicity in breast cancer cells which seems to be related to the effect of glycosaminoglycan receptors in stimulating the internalization of targeted nanoplatforms. ${ }^{17} \mathrm{miR}-101$ could also decrease the cell viability around $40 \%$, whereas miR-34a or let-7 could reduce the cell viability around $34 \%{ }^{1,24}$ Upregulation of miR-101 could arrest HSP and autophagy and regulate the function of let-7 miRNA family by blocking Line 28 Homolog B (lin28B) proteins. ${ }^{29}$ Let-7 and miR-101 have impact on HSS and targeting of downstream pathways ${ }^{1,6}$ like cyclooxygenase-2 (COX-2), ${ }^{29}$ BRCA family, RAS, ${ }^{1}$ and mTOR/HIF pathways. ${ }^{1}$ Heat can change the transcriptional level of heat shock gene and enforce it to encode the HSP. ${ }^{30}$ It could also induce the stress that activates COX-2 which is responsible for regulating the cell behavior. ${ }^{30}$ In parallel, autophagy mechanism was activated in response to protein dysregulation which tightly participate in cell survival. Generally, miR-101 targets ATG4D that induces the cleavage in major autophagosome component proteins 1A/1B-light chain 3 (LC3 $)^{10}$ and disrupts the autophagy pathway. In addition, miR-101 potently suppresses the mentioned proteins and pathways to activate the apoptotic pathways. Taken together, this observation highlighted the excellent synergic properties of miR-101 and laser in increasing the toxicity in breast cancer cells, especially in MCF7 (killed around 70\% of cells) without sensible necrosis in the defined intervals.

\section{Subcellular localization}

To study whether targeted or nontargeted nanoplatforms could specifically transport miRNA to the breast cancer cells, the nanoplatforms were labeled with FITC and scramble-cy5 (5-miR-101) based on electrostatic interaction detected by confocal microscope. For this purpose, the cells were treated 


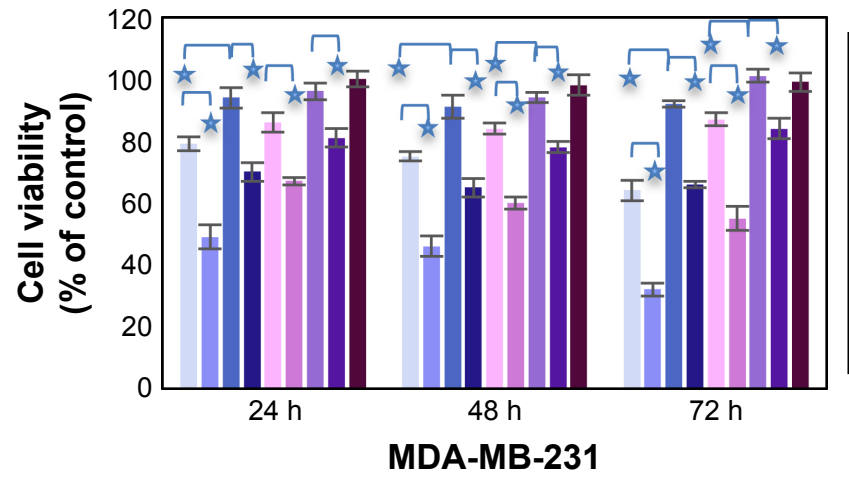

\begin{tabular}{|l|}
\hline GO-PEG-(P-L-Arg)/miR-101 \\
GO-PEG-(P-L-Arg)/miR-101-laser \\
GO-PEG-(P-L-Arg) \\
GO-PEG-(P-L-Arg)-laser \\
GO-PEG/miR-101 \\
GO-PEG/miR-101-laser \\
GO-PEG \\
GO-PEG-laser \\
Control-laser
\end{tabular}

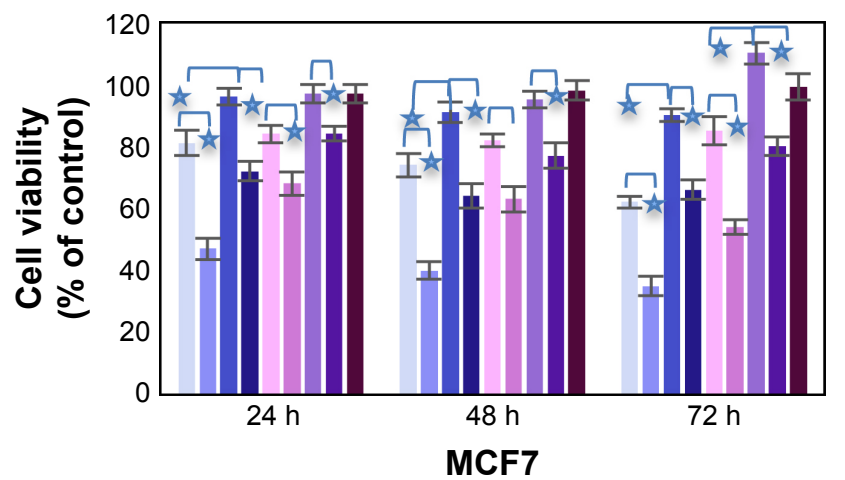

miR-101-(P-L-Arg-PEG-GO)

miR-101-(P-L-Arg-PEG-GO)-laser

- P-L-PEG-GO

- P-L-PEG-GO-laser

miR-101-(PEG-GO)

miR-101-(PEG-GO)-laser

- PEG-GO

- PEG-GO-laser

- Control-laser

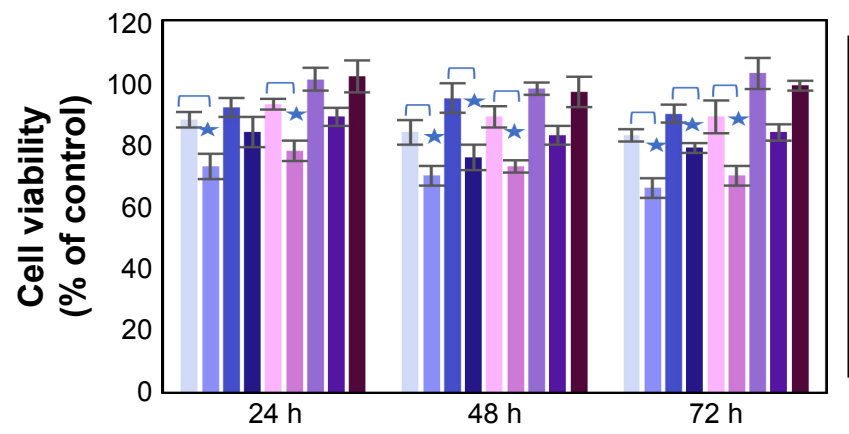

miR-101-(P-L-Arg-PEG-GO)

- miR-101-(P-L-Arg-PEG-GO)-laser

- P-L-PEG-GO

- P-L-PEG-GO-laser

miR-101-(PEG-GO)

miR-101-(PEG-GO)-laser

- PEG-GO

- PEG-GO-laser

- Control-laser

HU-02

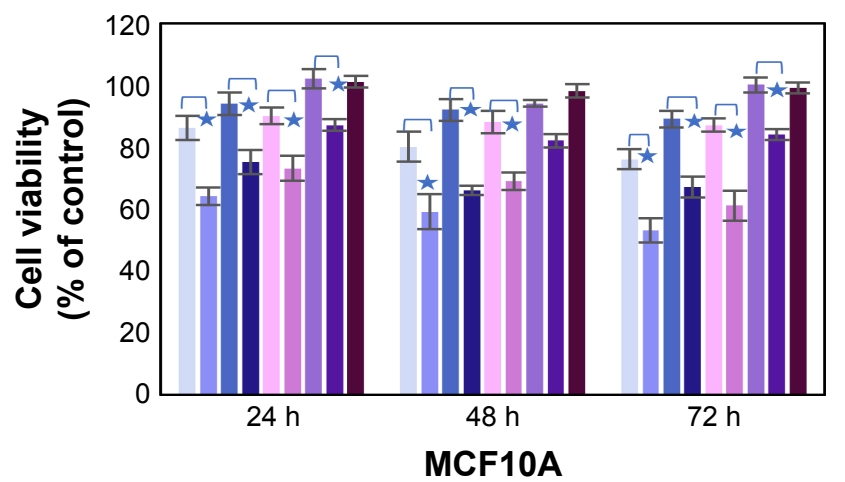

miR-101-(P-L-Arg-PEG-GO)

- miR-101-(P-L-Arg-PEG-GO)-laser

- P-L-Arg-PEG-GO

- P-L-Arg-PEG-GO-laser

miR-101-(PEG-GO)

miR-101-(PEG-GO)-laser

- PEG-GO

- PEG-GO-laser

- Control-laser

Figure 5 Cell viability was detected by MTT assay in all cell lines after 24, 48, and $72 \mathrm{~h}$. Values of the experiment were represented as mean \pm SD, where the treatments were performed in triplicate. ${ }^{\star}$ Shows significance correlation $<0.05$.

Abbreviations: GO, graphene oxide; PEG, polyethylene glycol; P-L-Arg, poly-L-arginine.

with GO-PEG-(P-L-Arg)/FITC/scramble-cy5 and GO-PEG/ FITC/scramble-cy5 for 90 min. Rate of internalization in GOPEG-(P-L-Arg) was dramatically greater than that in GO-PEG in MCF7 cell line (Figure 8A). GO-PEG-(P-L-Arg)/FITC completely covered the cytoplasm, whereas GO-PEG/FITC was poorly detected and commonly visualized in a membrane that may need more time to uptake or higher concentration. Besides that, fluorescence signals of cy5 and FITC were 

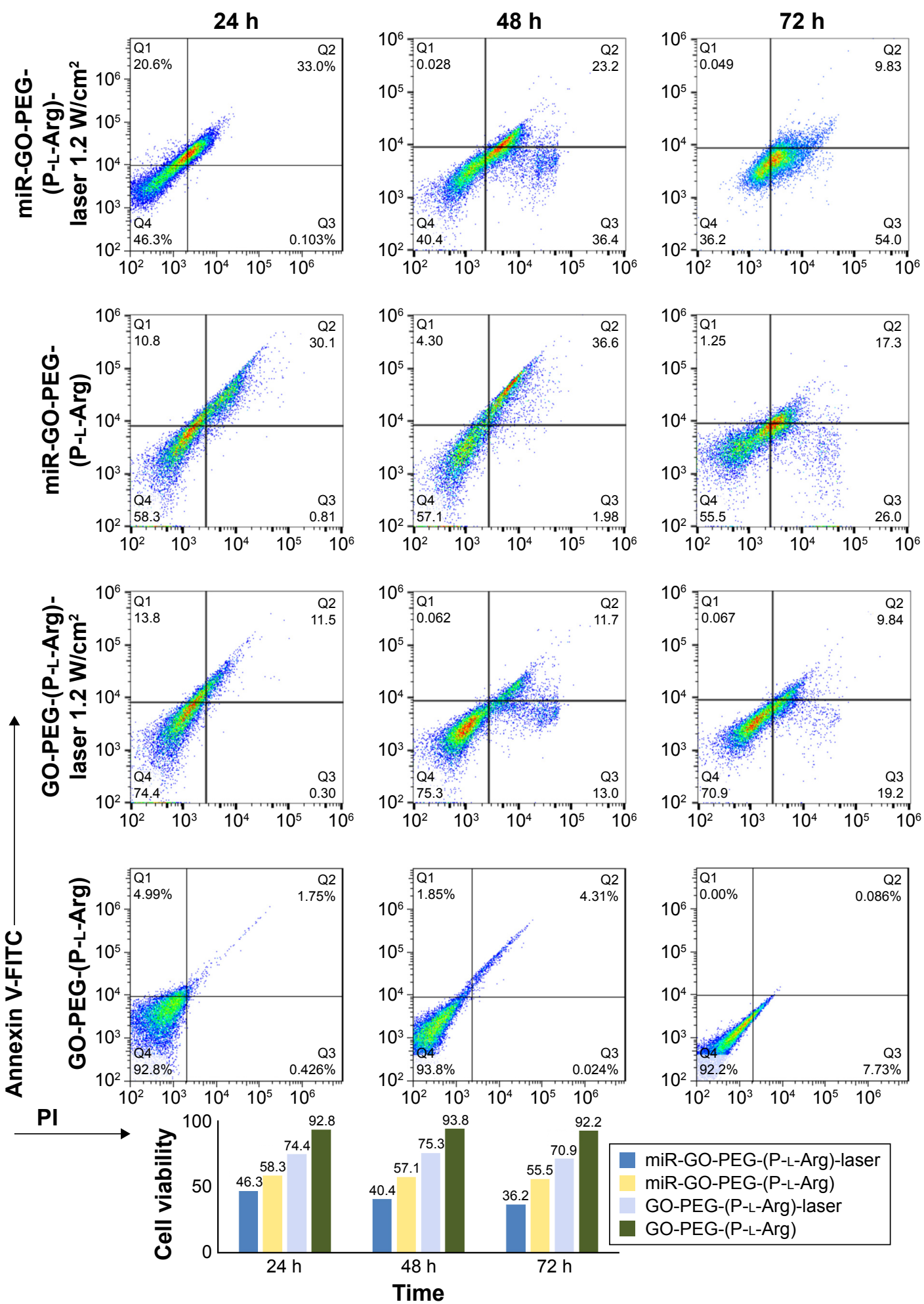

Figure 6 Amount of apoptosis and necrosis was detected by Annexin/PI kit for GO-PEG-(P-L-Arg), GO-PEG-(P-L-Arg)/miR-I0I with and without laser irradiation. The viability of cells is visualized by bar chart.

Abbreviations: GO, graphene oxide; PEG, polyethylene glycol; P-L-Arg, poly-L-arginine; FITC, fluorescein isothiocyanate; PI, propidium iodide.

observed in all cells when treated with GO-PEG-(P-L-Arg)/ FITC/scramble-cy5 (Figure 8B). Breast cell lines showed remarkably higher fluorescence intensity in comparison with normal cells in the same condition. Generally, surface modifications could enhance the interaction of nanoplatforms with biomolecules, protect the enzymatic degradation of genes, reduce the interaction with plasma proteins, and activate the targeting pathways, ${ }^{31}$ which prevented the 

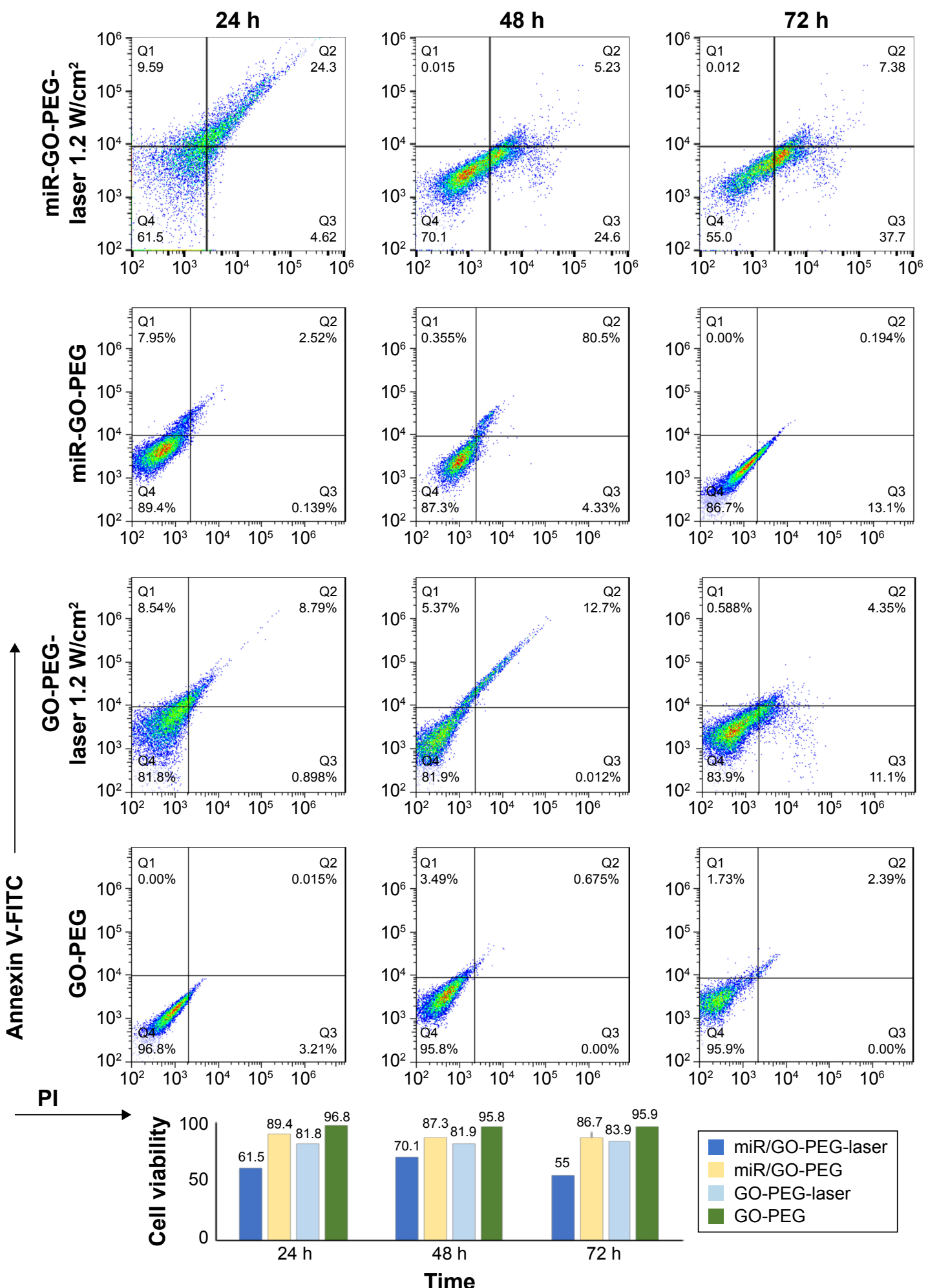

Figure 7 Amount of apoptosis and necrosis was detected by Annexin/PI kit for GO-PEG, GO-PEG/miR-I0I with and without laser irradiation. The viability of cells is visualized by bar chart.

Abbreviations: GO, graphene oxide; PEG, polyethylene glycol; P-L-Arg, poly-L-arginine; FITC, fluorescein isothiocyanate; PI, propidium iodide.

accumulation of nanoplatforms in normal tissues. P-L-Arg as cationic cell penetrating peptide facilitated the rapid internalization of nanoplatforms through clathrin-mediated endocytosis into the cells. ${ }^{32}$ P-L-Arg was able to directly interact with phosphates on the lipid part of membrane ${ }^{16,32}$ and targeted the proteoglycan receptors, especially heparin sulfate on breast cancer cell lines which was overexpressed in cancer cells like MCF7. ${ }^{19}$ To quantitatively estimate 
A

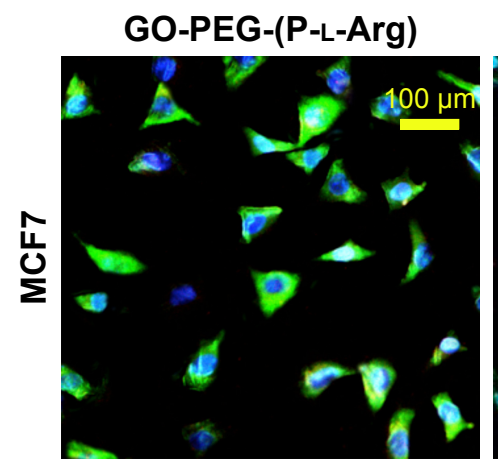

GO-PEG

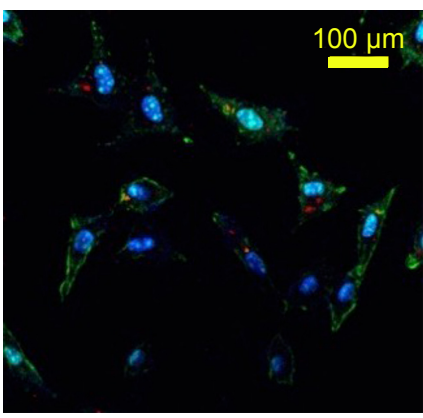

B
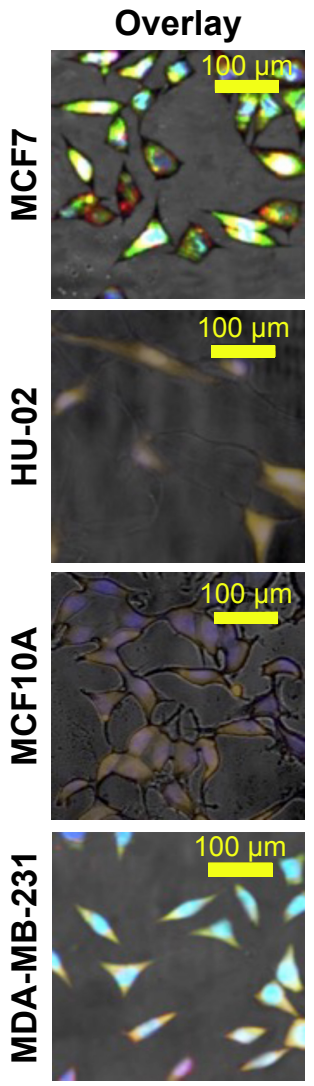

Merge
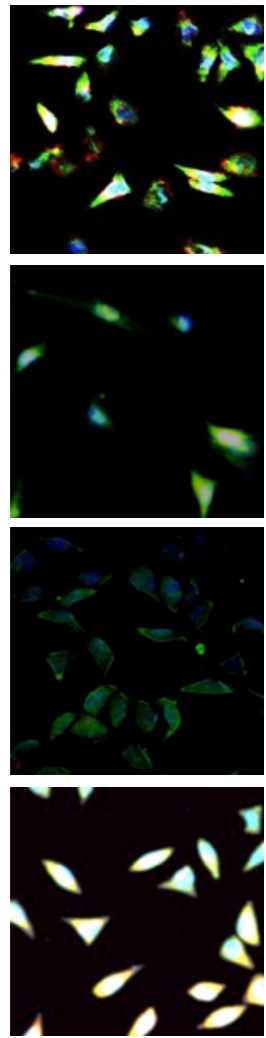
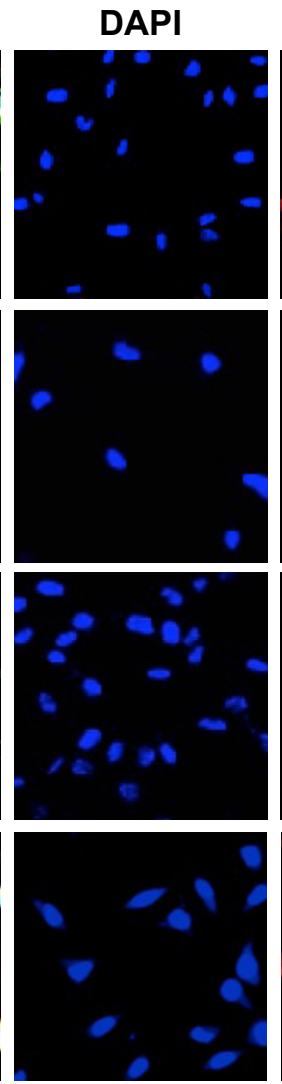

CY5
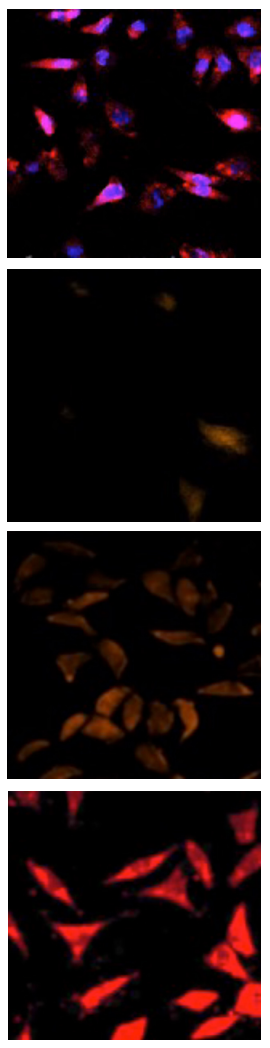

FITC
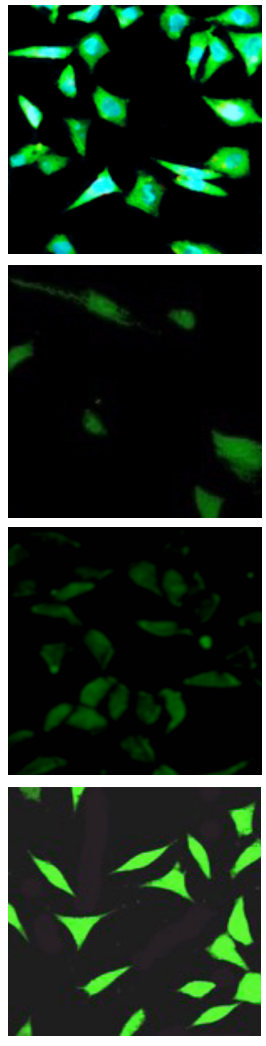

Figure 8 Confocal microscopy of different cell internalization of FITC/GO-PEG and FITC/GO-PEG-(P-L-Arg) in MCF7 cell line during 90 min (A). Cellular localization of FITC/GO-PEG-(P-L-Arg)/scramble-cy5 was visualized by confocal microscope in different cell lines (B). Green: FITC, red: CY5-scramble; and blue: DAPI.

Abbreviations: GO, graphene oxide; PEG, polyethylene glycol; P-L-Arg, poly-L-arginine; FITC, fluorescein isothiocyanate.

the cellular internalization of nanoplatform, the cells were incubated with GO-PEG-(P-L-Arg)/FITC and GO-PEG/ FITC before being analyzed by flow cytometry. As it can be observed in Figure 9, the cells treated with GO-PEG-(PL-Arg)/FITC indicated $89.1 \%, 86.1 \%, 57.7 \%$, and $43.9 \%$ uptake at $90 \mathrm{~min}$ in MCF7, MDA, MCF10A, and HU-02 cells, respectively. Furthermore, the highest uptake of GO-PEG/ FITC was detected in MCF7 (42.3\%) and the least uptake was measured in HU-02 (13.2\%). To further confirm the targeting efficiency of GO-PEG-(P-L-Arg) nanoplatform, the same analysis in the same concentration $(4 \mu \mathrm{g} / \mathrm{mL})$ and a situation was performed by lipofectamine 2000/FITC.
Data showed $73.3 \%, 73.7 \%, 69.5 \%$, and $57 \%$ uptake by MCF7, MDA, MCF10A, and HU-02 cells, respectively. This amount of uptake was less than GO-PEG-(P-L-Arg) nanoplatform in breast cancer cell lines, whereas the uptake was increased in normal cells that visualized less selectivity in delivery. Results also provided strong evidence to show the efficacy of our nanoplatform and translocating the cargoes across the cell and delivering their payload. The excellent affinity of GOPEG-(P-L-Arg) nanoplatform to breast cancer cells might be explained by the smart composition. First, functionalization converted flat $\mathrm{GO}$ sheets to 3D structure; GO surface is able to be grafted with many functional groups, ${ }^{15,25}$ which show 

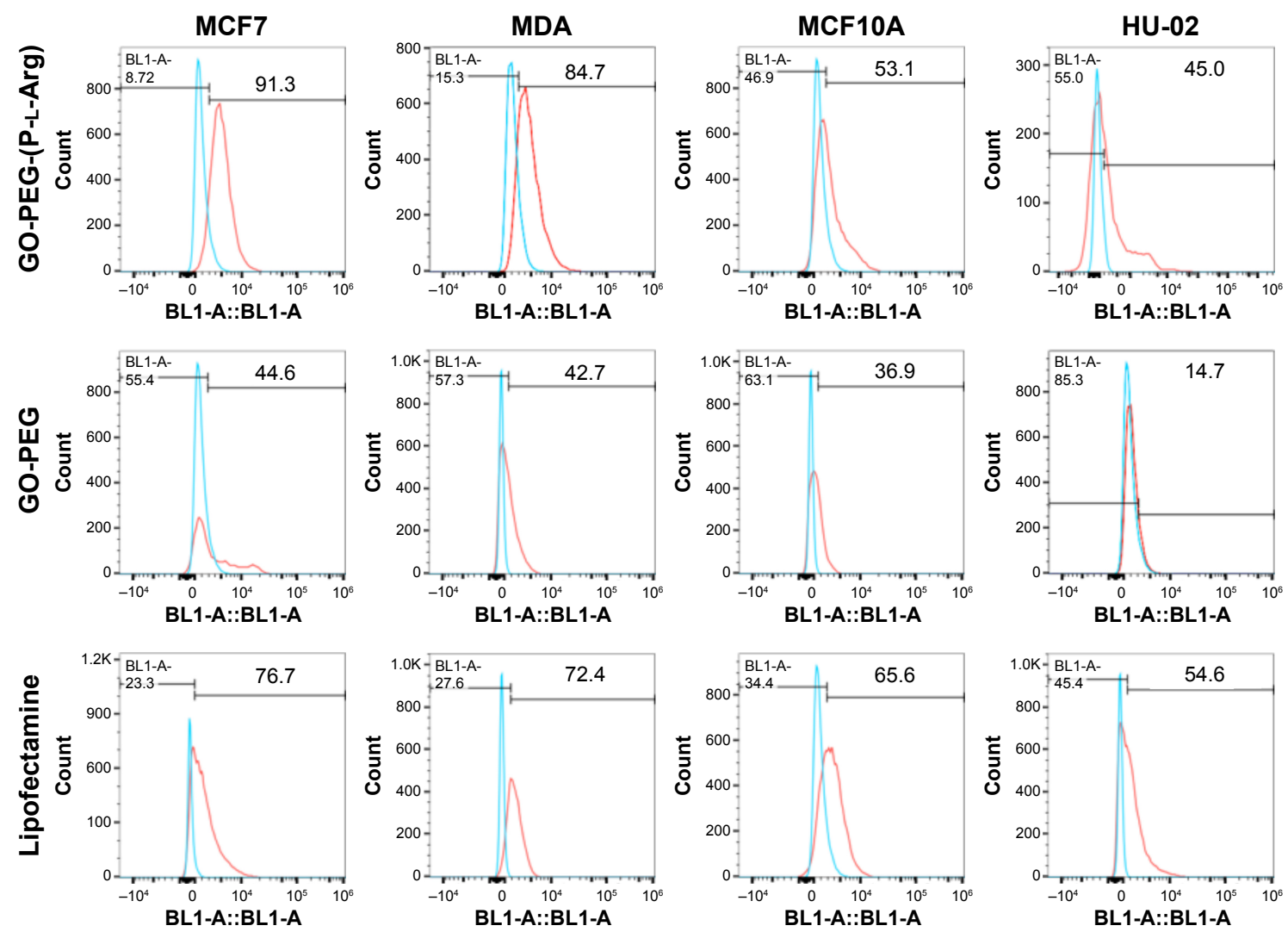

Figure 9 Cellular uptake of nanoplatforms-FITC in comparison with Lipofectamine (2000)-FITC in the same concentration was measured by flow cytometry in all cell lines. Abbreviations: GO, graphene oxide; PEG, polyethylene glycol; P-L-Arg, poly-L-arginine; FITC, fluorescein isothiocyanate.

new characteristics and properties for GO. Second, coordination of component in heterostructure resulted to achieve major goals; the presence of linear and long chains of P-L-Arg with different length and short chains of PEG could be effective in inducing the interaction of nanoplatforms with cell membrane receptors due to optimized distance, possibility of interaction, flexibility, and improved density of targeting agent. ${ }^{20} \mathrm{We}$ also found that P-L-Arg, as a targeting agent, dramatically increased the efficiency of uptake, whereas poly-Llysine and polymers like chitosan or derivative were less successful to increase the amount of uptake. ${ }^{23,24}$ The cationic liposome such as lipofectamine also showed a statistically low level of uptake compared with the nanoplatform prepared in this study. Lipofectamine also indicated higher rates of uptake in normal cells that causes various side effects on normal cells. In the case of MCF7, the rate of internalization of our nanoplatforms was more than this amount at MDA cells that related to overexpressed heparin sulfate receptors in the cell membrane. ${ }^{19}$ P-L-Arg targets glycosaminoglycan receptors specially heparin sulfate receptor that participates in nanoplatforms internalization. ${ }^{17,19}$ Lower rates of nanoplatforms were also internalized into normal cells (MCF10A and HU-02) due to less glycosaminoglycan receptors. Moreover, cationic modifications increased the electrostatic interaction with the cell membrane and increased the uptake by clathrin-dependent endocytosis. ${ }^{31}$ Besides that, a high positive charge of unfolding cationic peptide induced direct fusion of nanoplatforms across the membrane through interaction with phosphate in membrane.

\section{Quantification of gene release from nanoplatform/gene complexes}

Low nuclease protection and weak chemical stability of the naked double strand or plasmid miRNA induces short half-lives ${ }^{31}$ and poor cellular uptake, while vectors could interact with miRNA and cover the sensitive site of miRNA from nuclease activity that promotes the massive transportation of miRNA. miR-101 is one of the major miRNAs that is commonly decreased twofold in breast cancer cells, while overexpression of miR-101 promotes apoptosis and suppresses cancer cells. ${ }^{3,4}$ To detect the efficiency of nanoplatforms to transfect pDNA or dsmiR, we performed qRTPCR on miR-101 expression after transfection (Figure 10). The nanoplatforms/dsmiR complex containing P-L-Arg increased the internalization $\sim 8$-fold greater than those nanoplatforms without P-L-Arg in breast cancer cells that 


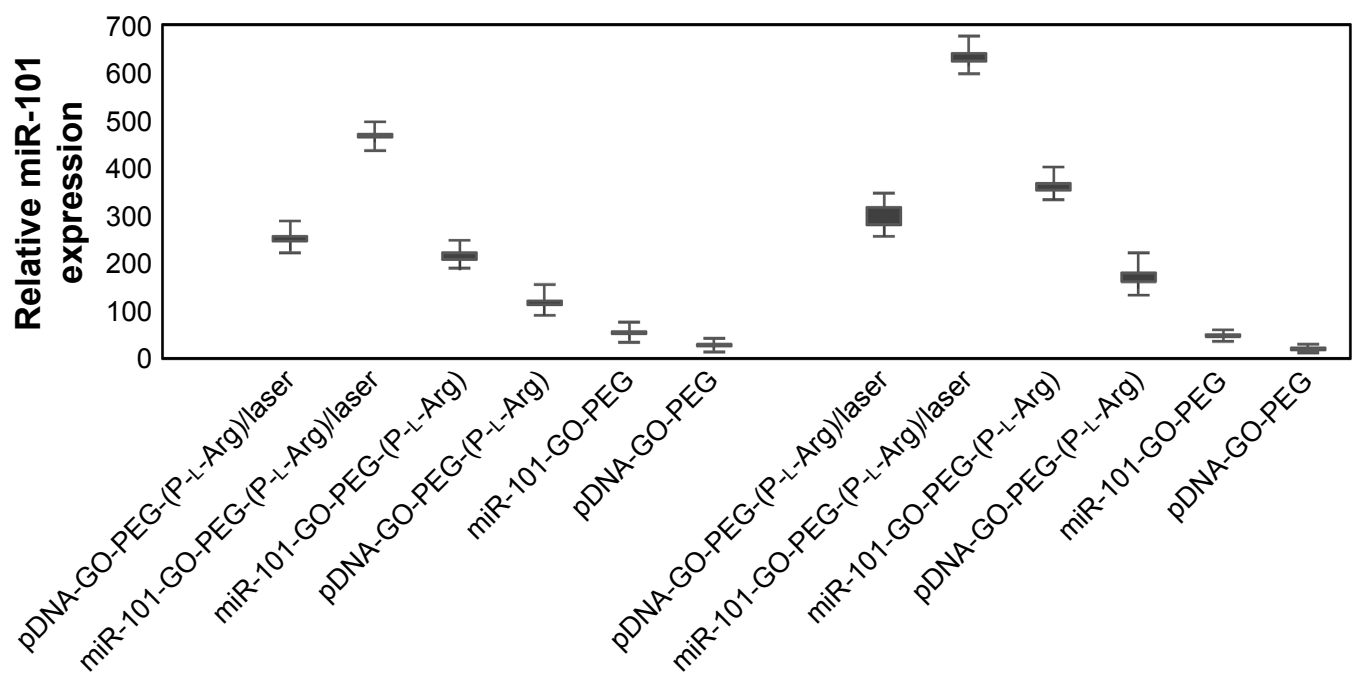

MDA

MCF7

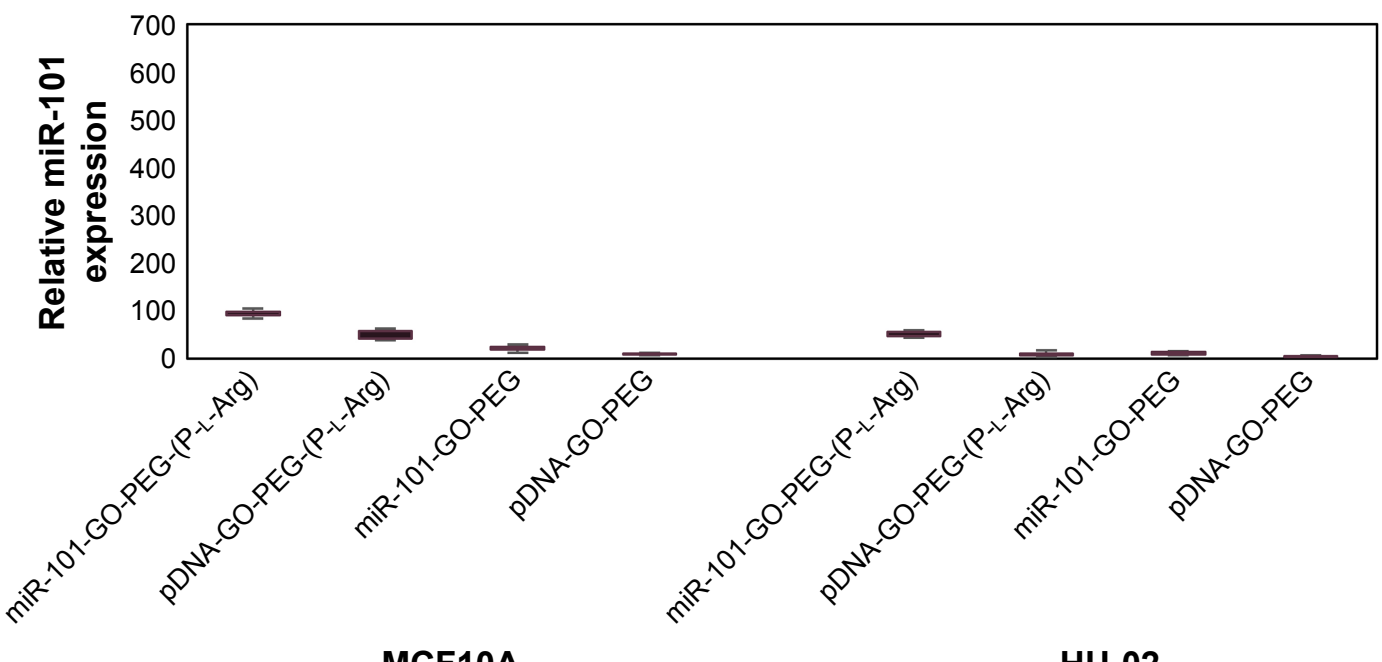

MCF10A

HU-02

Figure 10 Relative expression of nanoplatforms/miR-I0I (4:I), naked miR-I0I, and laser-irradiated nanoplatforms/miR-I0I. All samples have a negative control and repeated three times.

Abbreviations: GO, graphene oxide; PEG, polyethylene glycol; P-L-Arg, poly-L-arginine.

indicated cell receptor responses to the targeting factor in breast cancer cells. MDA and MCF7 cells showed more efficient gene transfection with pDNA or dsmiR than normal cells (MCF10A and HU-02). Accordingly, the expression of dsmiR-101 in MCF7 was $~ 7$-fold greater than HU-02 and 3.5-fold more than MCF10A cells. While the treated cells were irradiated by NIR laser, the amount of miR-101 expression dramatically increased. Meanwhile, thermal therapy decreased affinity of nanoplatforms to genes, which induced to release genes. Also, temperature increased sensitivity of tumor cells with activating stress factors. ${ }^{1}$ Furthermore, the outcome of pDNA transfection like dsmiR transfection pattern indicated successful internalization and release of miR-101 in both cancer cell line in comparison with normal cells. Thus, the designed smart nanoplatform was induced to well interact with cancer cells and led to high cellular expression of miRNA.

\section{ICC and WB}

To determine the potential of nanoplatforms in gene transfection and regulate target proteins, we performed ICC and WB to detect subsequent miR-101 transfection on Stathmin 1 expression (Figure 11). ICC and WB assay indicated that overexpression of miR-101 downregulated the expression of Stathmin 1 gene and consequently decreased the amount of Stathmin1 protein which is in well agreement with the previous reports. ${ }^{3,5,8}$ Stathmin 1 is a small cytosolic regulatory protein that is involved in cellular 
A

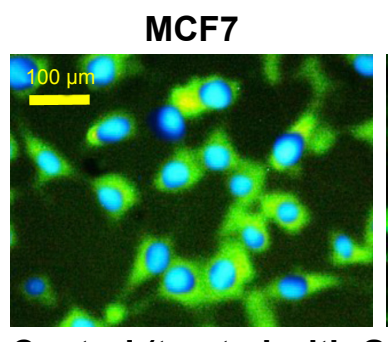

Control (treated with GO-PEG-(P-L-Arg))

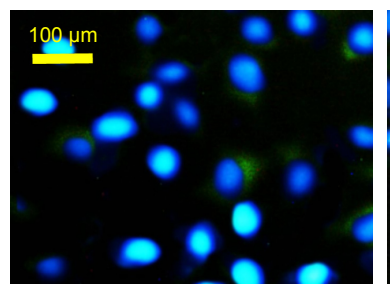

Sample (treated with GO-PEG-(P-L-Arg)-miR-101)
MDA-MB-231
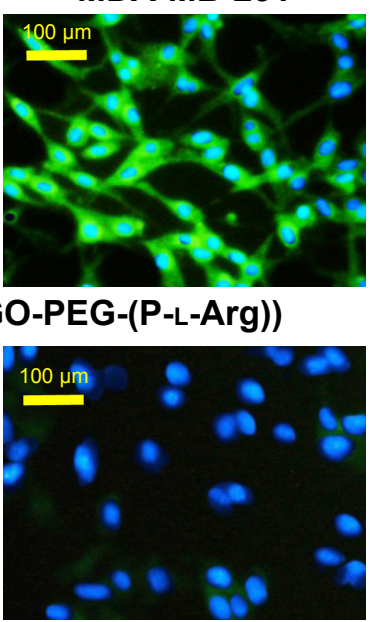

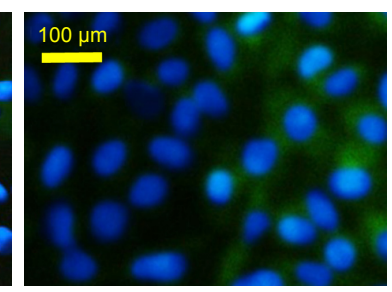

MCF10A

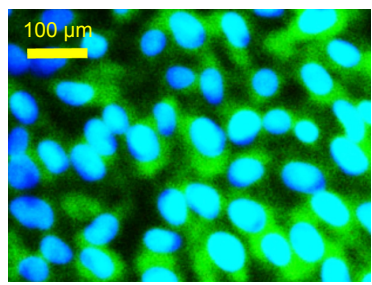

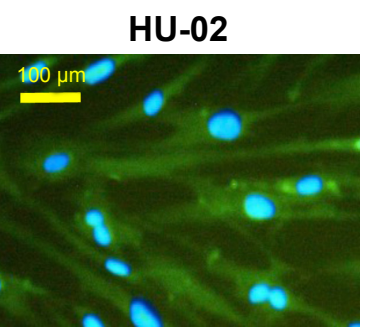
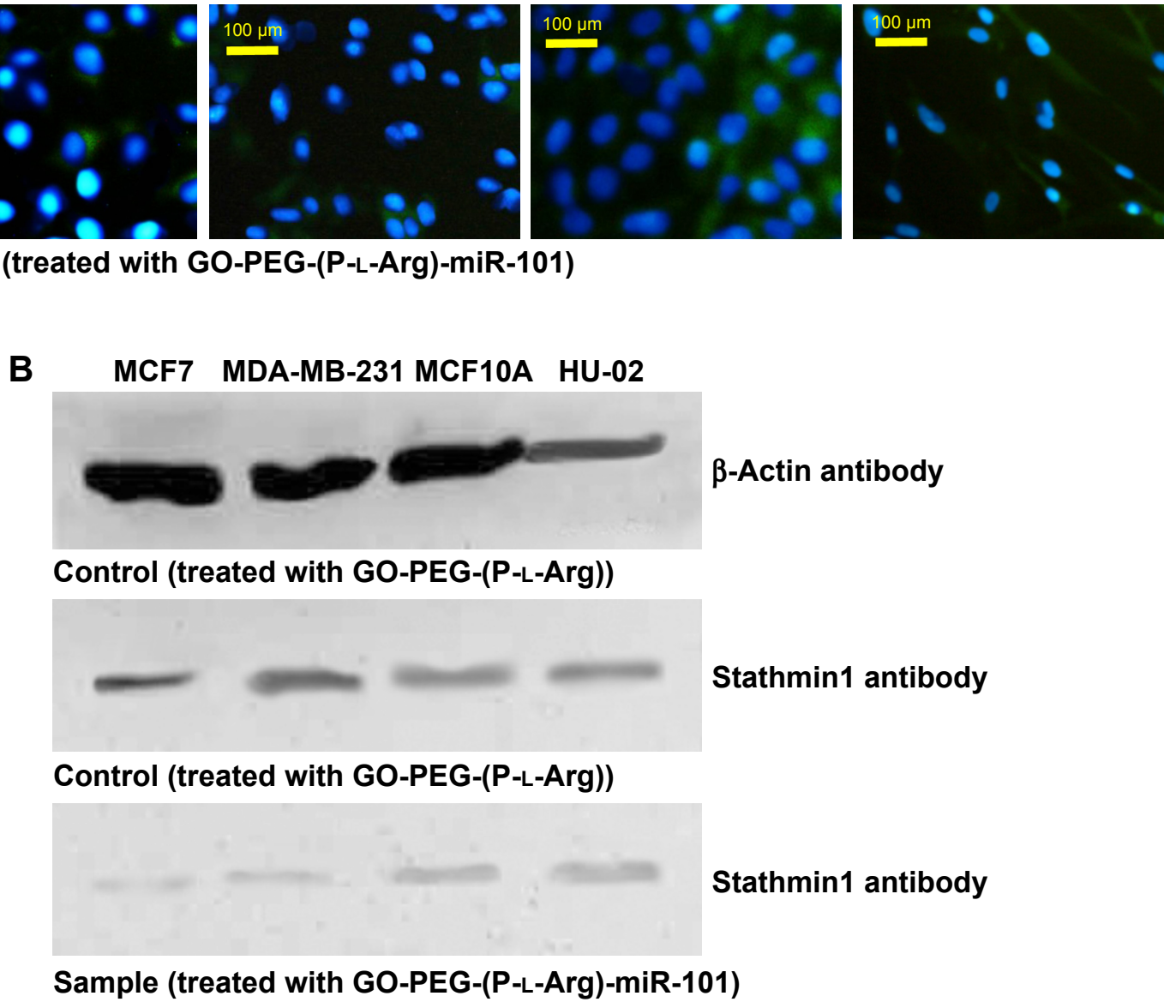

Figure I I miR-I0I overexpression suppressed stathmin I expression in breast cancer cells. The protein level of stathmin I was detected $48 \mathrm{~h}$ after treated cells with GO-PEG-(P-L-Arg)-miR-I0I by ICC assay $(\mathbf{A})$ and $\mathrm{WB}$ assay (B).

Abbreviations: GO, graphene oxide; PEG, polyethylene glycol; P-L-Arg, poly-L-arginine; ICC, immunocytochemistry; WB, Western blotting.

proliferation, differentiation, and cell cycle. Moreover, this phosphoprotein plays an important role in malignant tumors and mediates the metastatic breast cancer by regulating the cell signaling pathways. In general, overexpression of Stathmin 1 decreases the sensitivity to chemotherapeutic drugs $^{33}$ and promotes the malignancy in cancer cells by phosphoinositide 3-kinase (mammalian TOR), and HSP $90(\mathrm{PI} 3 \mathrm{~K} / \mathrm{mTOR} / \mathrm{HSP} 90)^{8}$ that affect the polymerization of microtubules ${ }^{33}$ through PI3K pathway or PI3K/mTOR/ HSP90. ${ }^{8}$ Many studies have confirmed that Stathmin1 is one of the specific targets of miR-101 which is upregulated in many cancers. ${ }^{8,27,33} \mathrm{miR}-101$ could promote apoptosis by regulating $\mathrm{p} 53,{ }^{8}$ suppresses autophagy, and decreases the microtubule instability. Breast cancer cells specially MCF7 cells revealed downregulation of miR-101 and higher level of Stathmin1 protein. Transfection of miR-101 induced to suppress Stathmin1 gene and decrease the level of Stathmin 1 proteins. Conversely, control cells (treated only with nanoplatforms) indicated high amount of Stathmin 1 proteins in ICC assay as well as WB results confirmed higher levels of this protein in control cells. Both the assays confirmed that the nanoplatforms successfully protected, transported, and overexpressed miR-101, which led to clear inhibition on Stathmin1 level in breast cancer cells. 


\section{Conclusion}

In the present study, the surface of GO sheet was decorated with amine-terminated PEG and P-L-Arg. Before functionalization, GO sheets were carboxylated to improve the content of carboxyl groups and enhance covalent reaction with functional groups. Long linear chains of P-L-Arg were employed as a targeting agent to increase the rate of uptake, whereas PEGylation modulated the extra charges of P-L-Arg and improved the biocompatibility of nanoplatform. Guanidine groups in lateral chains of P-L-Arg increased the capacity of nanoplatforms to load, cover, and protect different types of genes for efficient and safe delivery that activated the proton sponge effect during acidification. The flexibility and suitable length of these chains initiated the interaction with cells through recognition receptors. Furthermore, GO-PEG(P-L-Arg) nanoplatform had a versatile function due to their unique properties of small size, conductivity, high payload, and the ability to protect the gene for safe delivery. The nanoplatform in complex with miR-101 carefully adjusted the apoptosis, autophagy, and HSS. In this study, Stathmin1 protein was targeted and suppressed by miR-101 which induced apoptosis and downregulated the subunit of stress like autophagy and HSPs. Privilege strategy in designing nanoplatform to deliver miR-101 along with thermal therapy provided synergic effects which induced to increase the temperature around nanoplatforms, rupture endosomes, enhance the gene release, and massively boost the rate of apoptosis. Further investigations are needed to optimize the designed system for in vivo applications.

\section{Acknowledgments}

The authors would like to thank the Nanotechnology Research Centre of Tehran University of Medical Sciences and Stem Cell Technology Research Center for their support.

\section{Disclosure}

The authors report no conflicts of interest in this work.

\section{References}

1. Yin PT, Shah BP, Lee KB. Combined magnetic nanoparticle-based microRNA and hyperthermia therapy to enhance apoptosis in brain cancer cells. Small. 2014;10(20):4106-4112.

2. Varambally S, Cao Q, Mani R-S, et al. Genomic loss of microRNA-101 leads to overexpression of histone methyltransferase EZH2 in cancer. Science. 2008;322(5908):1695-1699.

3. Li J-T, Jia L-T, Liu N-N, et al. MiRNA-101 inhibits breast cancer growth and metastasis by targeting CX chemokine receptor 7. Oncotarget. 2015; 6(31):30818.

4. Zhang J-G, Guo J-F, Liu D-L, Liu Q, Wang J-J. MicroRNA-101 exerts tumor-suppressive functions in non-small cell lung cancer through directly targeting enhancer of zeste homolog 2. J Thorac Oncol. 2011;6(4): 671-678.
5. Bo L, Su-Ling D, Fang L, et al. Autophagic program is regulated by miR-325. Cell Death Differ. 2014;21(6):967-977.

6. Dokladny K, Myers OB, Moseley PL. Heat shock response and autophagy - cooperation and control. Autophagy. 2015;11(2):200-213.

7. Zabirnyk O, Yezhelyev M, Seleverstov O. Nanoparticles as a novel class of autophagy activators. Autophagy. 2007;3(3):278-281.

8. Biaoxue R, Xiguang C, Hua L, Shuanying Y. Stathmin-dependent molecular targeting therapy for malignant tumor: the latest 5 years' discoveries and developments. $J$ Transl Med. 2016;14(1):279.

9. Joydeep D, Choi Y-J, Yasuda H, et al. Efficient delivery of C/EBP beta gene into human mesenchymal stem cells via polyethylenimine-coated gold nanoparticles enhances adipogenic differentiation. Sci Rep. 2016; 6:37480.

10. Roberts R, Al-Jamal WT, Whelband M, et al. Autophagy and formation of tubulovesicular autophagosomes provide a barrier against nonviral gene delivery. Autophagy. 2013;9(5):667-682.

11. Zhang B, Wei P, Zhou Z, Wei T. Interactions of graphene with mammalian cells: molecular mechanisms and biomedical insights. Adv Drug Deliv Rev. 2016;105:145-162.

12. Zhu H, Gao L, Jiang X, et al. Positively charged graphene oxide nanoparticle: precisely label the plasma membrane of live cell and sensitively monitor extracellular pH in situ. Chem Commun (Camb). 2014;50(28): 3695-3698.

13. Chen J, Liu H, Zhao C, et al. One-step reduction and PEGylation of graphene oxide for photothermally controlled drug delivery. Biomaterials. 2014;35(18):4986-4995.

14. Robinson JT, Tabakman SM, Liang Y, et al. Ultrasmall reduced graphene oxide with high near-infrared absorbance for photothermal therapy. J Am Chem Soc. 2011;133(17):6825-6831.

15. Ou L, Song B, Liang H, et al. Toxicity of graphene-family nanoparticles: a general review of the origins and mechanisms. Part Fibre Toxicol. 2016;13(1):57

16. Verdurmen WPR, Wallbrecher R, Schmidt S, et al. Cell surface clustering of heparan sulfate proteoglycans by amphipathic cell-penetrating peptides does not contribute to uptake. J Control Release. 2013; 170(1):83-91.

17. Zern BJ, Chu H, Osunkoya AO, Gao J, Wang Y. A biocompatible arginine-based polycation. Adv Funct Mater. 2011;21(3):434-440.

18. Plianwong S, Opanasopit P, Ngawhirunpat T, Rojanarata T. Chitosan combined with poly-L-arginine as efficient, safe, and serum-insensitive vehicle with RNase protection ability for siRNA delivery. BioMed Res Int. 2013;2013:574136.

19. Morimoto-Tomita M, Uchimura K, Bistrup A, et al. Sulf-2, a proangiogenic heparan sulfate endosulfatase, is upregulated in breast cancer. Neoplasia. 2005;7(11):1001-1010.

20. Cruz LJ, Tacken PJ, Fokkink R, Figdor CG. The influence of PEG chain length and targeting moiety on antibody-mediated delivery of nanoparticle vaccines to human dendritic cells. Biomaterials. 2011;32(28): 6791-6803.

21. Feng L, Yang X, Shi X, et al. Polyethylene glycol and polyethylenimine dual-functionalized nano-graphene oxide for photothermally enhanced gene delivery. Small. 2013;9(11):1989-1997.

22. Abadeer NS, Murphy CJ. Recent progress in cancer thermal therapy using gold nanoparticles. J Phys Chem C. 2016;120(9):4691-4716.

23. Kar M, Tiwari N, Tiwari M, Lahiri M, Gupta SS. Poly-L-arginine grafted silica mesoporous nanoparticles for enhanced cellular uptake and their application in DNA delivery and controlled drug release. Part Part Syst Charact. 2013;30(2):166-179.

24. Deng X, Cao M, Zhang J, et al. Hyaluronic acid-chitosan nanoparticles for co-delivery of MiR-34a and doxorubicin in therapy against triple negative breast cancer. Biomaterials. 2014;35(14):4333-4344.

25. Liu Z, Robinson JT, Sun X, Dai H. PEGylated nanographene oxide for delivery of water-insoluble cancer drugs. $J$ Am Chem Soc. 2008; 130(33): 10876-10877.

26. Huang P, Zhu H, Jing L, Zhao Y, Gao X. Graphene covalently binding aryl groups: conductivity increases rather than decreases. ACS Nano. 2011;5(10):7945-7949. 
27. Zhang X, Ji J, Yang Y, Zhang J, Shen L. Stathmin1 increases radioresistance by enhancing autophagy in non-small-cell lung cancer cells. Onco Targets Ther. 2016;9:2565.

28. Kim J, Kim H, Kim WJ. Single-layered MoS2-PEI-PEG nanocomposite-mediated gene delivery controlled by photo and redox stimuli. Small. 2016;12(9):1184-1192.

29. Wang L, Zhang L-F, Wu J, et al. IL-1 $\beta$-mediated repression of microRNA-101 is crucial for inflammation-promoted lung tumorigenesis. Cancer Res. 2014;74(17):4720-4730.

30. Rossi A, Coccia M, Trotta E, Angelini M, Santoro MG. Regulation of cyclooxygenase-2 expression by heat: a novel aspect of heat shock factor 1 function in human cells. PLoS One. 2012;7(2):e31304.
31. Conde J, Arnold CE, Tian F, Artzi N. RNAi nanomaterials targeting immune cells as an anti-tumor therapy: the missing link in cancer treatment? Mater Today. 2016;19(1):29-43.

32. Verma A, Stellacci F. Effect of surface properties on nanoparticle-cell interactions. Small. 2010;6(1):12-21.

33. Alli E, Bash-Babula J, Yang J-M, Hait WN. Effect of stathmin on the sensitivity to antimicrotubule drugs in human breast cancer. Cancer Res. 2002;62(23):6864-6869. 


\section{Supplementary materials}

Methods

\section{Preparation and amplification of plasmid DNA (pDNA)}

The sequence containing human miR-101 (around $400 \mathrm{bp}$ ) was replicated using polymerase chain reaction (PCR; coloning-miR-101-1 primers). Consequently, the PCR products and backbone plasmids (pCDH-CMV-MCS-EF1cGFP-T2A-Puro, 8,189 bp) were digested by restriction enzymes (EcoR1 and BamH1) and ligated in order to locate the miR-101 sequence into the plasmid vector. After that, the plasmids were transfected into the STBL4 bacteria and finally the plasmid was purified from the bacteria (Invitrogen kit, Tehran, Iran). The plasmid was sequenced by Macrogene Company (Seoul, Korea) to confirm the presence of miR-101 sequence in the designed pDNA. STBL 4 bacteria containing plasmid-miR-101 were incubated in Luria Broth (LB, with ampicillin) at $37^{\circ} \mathrm{C}$ and shacked for maximum $16 \mathrm{~h}$. After that, the bacteria were collected by centrifugation and purified according to the plasmid purification kit (Qiagen NV, Venlo, the Netherlands). Finally, the pDNA (7,200 bp) was captured in elution buffer, run by gel electrophoresis, and concentration was measured by Nanodrop.

List of primers and miRNA sequence for gene delivery and following experiments

Sequence: hsa-miR-101 RNA major: 5-UACAGUAC UGUGAUAACUGAA-3

hsa-miR-101* RNA minor: 5-CAGUUAUCACAGUG CUGAUGCU-3

Scramble: CY5-miR-101: 5-UACAGUACUGUGAU AACUGAA-CY5

Cloning primer: Forward: 5-CCGGAATTCGCAGT TGTTCATCCTCATTA-3

Reverse: 5-CGGGATCCAGGCAAAGAGAAGC AGAAT-3

Reverse transcription primer: Forward Snord: CGTGTAGAGCACCGAAAACC

Reverse Snord: CAC TCA GAC CGC GTT CTC TC

Reverse transcription primer: Forward miR-101: AGG CTC ATA CAG TAC TGT GAT AAC

Reverse miR-101: GAG CAG GGT CCG AGG T.
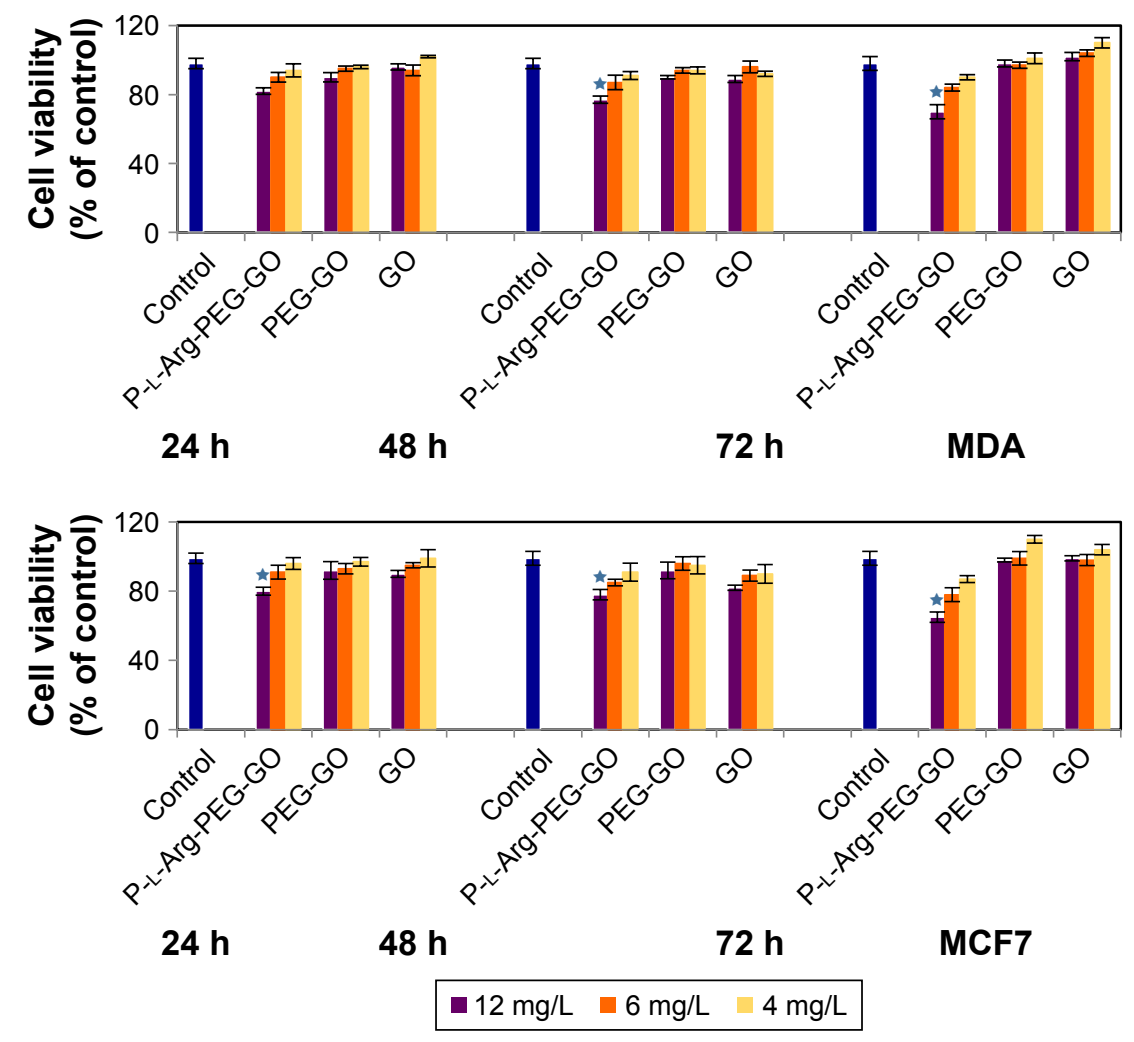

Figure SI (Continued) 

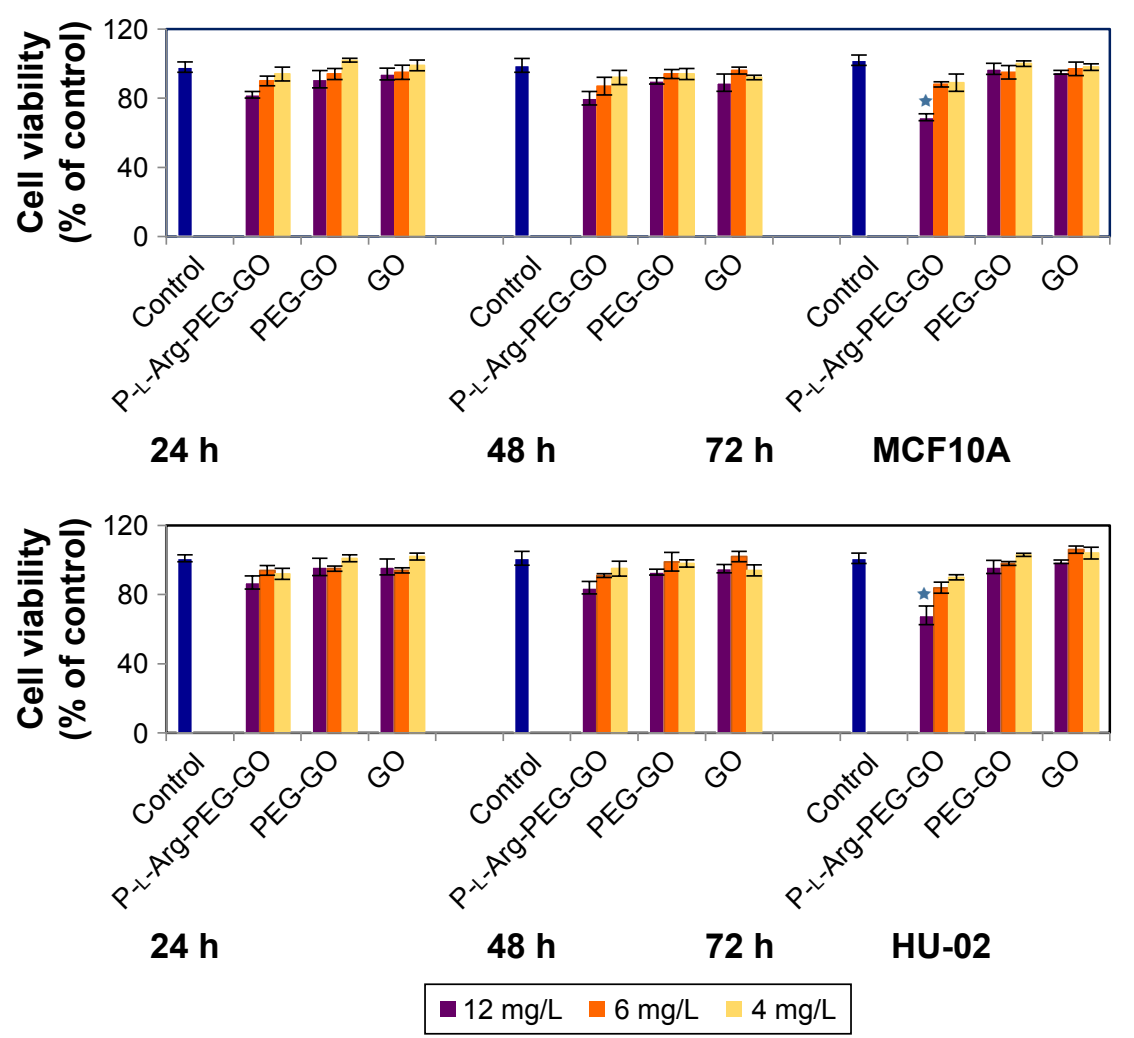

Figure SI Toxicity of nanoplatforms in various concentration was detected by MTT assay in MDA, MCF7, MCFIOA, and HU-02 for 24 , 48, and 72 h. Values of the experiment were represented as mean $\pm \mathrm{SD}$, where the treatments were performed in triplicate and each sample was compared with the control. ${ }^{\star}$ Shows significance correlation $<0.05$

Abbreviations: GO, graphene oxide; PEG, polyethylene glycol; P-L-Arg, poly-L-arginine.

\section{Publish your work in this journal}

The International Journal of Nanomedicine is an international, peerreviewed journal focusing on the application of nanotechnology in diagnostics, therapeutics, and drug delivery systems throughout the biomedical field. This journal is indexed on PubMed Central, MedLine, CAS, SciSearch $®$, Current Contents ${ }^{\circledR} /$ Clinical Medicine,
Journal Citation Reports/Science Edition, EMBase, Scopus and the Elsevier Bibliographic databases. The manuscript management system is completely online and includes a very quick and fair peer-review system, which is all easy to use. Visit http://www.dovepress.com/ testimonials.php to read real quotes from published authors. 